\title{
An overview of the sandfly fauna (Diptera: Psychodidae) followed by the detection of Leishmania DNA and blood meal identification in the state of Acre, Amazonian Brazil
}

\author{
Thais de Araujo-Pereira', Daniela de Pita-Pereira', Sandylere Moreira Baia-Gomes', \\ Mariana Boité ${ }^{2}$, Franklin Silva ${ }^{3}$, Israel de Souza Pinto ${ }^{4}$, Raimundo Leoberto Torres de Sousa ${ }^{1}$, \\ Andressa Fuzari ${ }^{5}$, Cristian de Souza ${ }^{5}$, Reginaldo Brazil ${ }^{5}$, Constança Britto ${ }^{1 /+}$ \\ ${ }^{1}$ Fundação Oswaldo Cruz-Fiocruz, Instituto Oswaldo Cruz, Laboratório de Biologia Molecular e Doenças Endêmicas, Rio de Janeiro, RJ, Brasil \\ ${ }^{2}$ Fundação Oswaldo Cruz-Fiocruz, Instituto Oswaldo Cruz, Laboratório de Pesquisa em Leishmanioses, Rio de Janeiro, RJ, Brasil \\ ${ }^{3}$ Fundação Oswaldo Cruz-Fiocruz, Centro De Desenvolvimento Tecnológico em Saúde, Laboratório de Modelagem de Sistemas Biológicos, \\ Rio de Janeiro, RJ, Brasil \\ ${ }^{4}$ Instituto Federal de Educação, Ciência e Tecnologia do Pará, Itaituba, PA, Brasil \\ ${ }^{5}$ Fundação Oswaldo Cruz-Fiocruz, Instituto Oswaldo Cruz, Laboratório de Doenças Parasitárias, Rio de Janeiro, RJ, Brasil
}

BACKGROUND In Acre state, Brazil, the dissemination of cutaneous leishmaniasis has increased in recent years, with limited knowledge of the potential Leishmania spp. vectors involved.

OBJECTIVES Here, data concerning the sandfly fauna of Brasiléia municipality, Leishmania DNA-detection rates and the identification of blood meal sources of insects captured in 2013-2015 are presented.

METHODS Parasite detection in female sandflies was performed individually by multiplex polymerase chain reaction (PCR) (Leishmania kDNA/sandfly cacophony-gene), with the identification of Leishmania spp. by hsp70-PCR and sequencing. The identification of blood gut-content from fed females was performed by $c y t b$-PCR and sequencing.

FINDINGS A total of 4,473 sandflies were captured. A subgroup of 864 non-blood-fed females evaluated for the presence of Leishmania DNA showed 2.9\% positivity for Leishmania (Viannia) braziliensis and L. (V.) guyanensis. The identification of blood meal sources was performed in 96 blood-fed females, allowing the identification of 13 vertebrate species. In nine/96 fed females, DNA from L. (V.) shawi, L. (V.) guyanensis, L. (V.) braziliensis and Endotrypanum sp. was detected.

MAIN CONCLUSIONS In Brumptomyia sp. and Evandromyia termitophila, the first report of Leishmania DNA-detection is provided in Acre; Nyssomyia shawi is implicated as potential vector of L. (V.) braziliensis and L. (V.) guyanensis for the first time in Brazil.

Key words: cutaneous leishmaniasis - sandflies - Leishmania DNA-detection - blood meal analysis - vector-borne disease

Leishmaniasis is a public health problem in 98 countries distributed across four continents (the Americas, Europe, Africa and Asia), with compulsory notification in 32 countries, including Brazil. The World Health Organization (WHO) estimates that 350 million people are at risk of contracting the infection, accounting for approximately 2 million new cases of the different clinical forms per year. Leishmaniasis is considered one of the six most important infectious diseases due to its high detection coefficient and capacity to produce deformities. ${ }^{(1)}$

\footnotetext{
doi: 10.1590/0074-02760200157

Financial support: CNPq (473859/2013-0, 305589/2015-6), FAPERJ (CNE E 05/2015), Fiocruz. CB (304358/2019-3) and RB are researcher fellows of CNPq, CB is research fellow of FAPERJ (CNE E-26/202.782/2018), TA-P is postdoctoral fellow of FAPERJ (E-26/202.287/2019), DP-P is postdoctoral fellow of PNPD/CAPES (31010016001P0).

+ Corresponding author: cbritto@ioc.fiocruz.br

(D) https://orcid.org/0000-0003-0788-7030

Received 06 April 2020

Accepted 05 October 2020
}

Cutaneous leishmaniasis (CL) is a zoonosis present in all Brazilian states ${ }^{(2)}$ that is caused by protozoa of the Leishmania genus (order Kinetoplastida, family Trypanosomatidae), which are transmitted by hematophagous sandflies of the subfamily Phlebotominae (family Psychodidae). It can affect humans when they accidentally participate in the natural cycle of maintenance of the disease because of activities that require their entry into forest environments or even due to the proximity of houses close to the edge of forests or even within them. ${ }^{(1)}$ CL is associated with a variety of dermotropic Leishmania species, with most of the diversity of parasites being found in the Amazon Region. The transmission of the etiological agents involves different sandfly species in specific associations with the parasites and their hosts, constituting the links of several transmission cycles that occur throughout the Brazilian territory. ${ }^{(3,4)}$

A total of 139,003 CL cases were registered in Brazil from 2012 to $2018,46 \%$ of which were reported only in the North Region, with predominance in the states of Pará, Amazonas, Rondônia and Acre. ${ }^{(2)}$ In the state of Acre, located southwest of the Amazon, CL is endemic with high rates of incidence and prevalence. ${ }^{(5-7)}$ Acre is geographically divided into two mesoregions (Vale do Juruá and Vale do Acre) and five microregions (Cru- 
zeiro do Sul, Tarauacá, Sena Madureira, Rio Branco and Brasiléia). Through the analysis of CL cases in these microregions from 2012 to 2018, Rio Branco $(2,652)$, Brasiléia $(2,025)$ and Sena Madureira $(1,142)$ showed the greatest numbers of reported cases, considering the total of 7,524 notifications throughout the state of Acre. . $^{(2)}$ There are no records of human cases of visceral leishmaniasis (VL) in Acre; nevertheless, there is a need for constant monitoring of the phlebotomine fauna and domestic animals, particularly dogs, since the occurrence of Lutzomyia longipalpis, the main vector of Leishmania (Leishmania) infantum in Brazil, has been recorded in the municipality of Assis Brasil (Acre) and in Bolivia and Peru. ${ }^{(8)}$

Brasiléia is located on the border with Cobija municipality (District of Pando - Bolivia); are highly dependent on commercial activities and represent areas of high endemicity for $\mathrm{CL}$, with great circulation of people between these cities. The present study aims to describe the sandfly fauna found in the municipality of Brasiléia and to evaluate the Leishmania DNA-detection index, followed by the molecular characterisation of the parasite species and, in parallel, the identification of blood meal sources in the captured insects. With the data obtained in this study, it will be possible to reveal new elements for better understanding the CL transmission cycle in the study area, which provides an attractive scenario for leishmaniasis research due to the scarcity of data in the region.

\section{MATERIALS AND METHODS}

Study area - Brasiléia municipality is located in the south of Acre state, Brazil $\left(11^{\circ} 00^{\prime} \mathrm{S} 68^{\circ} 44^{\prime} \mathrm{W}\right)$ (Figure) and is characterised by a restricted urban area and an extensive rural zone in the Amazonian forest, covering $3,916,505 \mathrm{~km}^{2}$ and an estimated population of 26,278 in- habitants. ${ }^{(9)}$ Brasiléia is located $237 \mathrm{~km}$ southern of Rio Branco, bordering the municipality of Cobija (District of Pando - Bolivia) and the Brazilian municipalities of Epitaciolândia, Assis Brasil, Sena Madureira and Xapuri. The vegetation is composed of dense and open tropical forest with predominance of palm trees; the presence of liana is common in the tropical rainforest. ${ }^{(10)}$ The region exhibits an equatorial tropical climate with temperatures varying between 22 and $33^{\circ} \mathrm{C}$ and annual precipitation of approximately $1,900 \mathrm{~mm}$, with higher rainfall intensity between the months of November to March and a dry period from May to August.

The survey was undertaken in Brasiléia municipality, in areas of current transmission of CL that were previously established according to human cases registered in recent years by the National Health Foundation (FUNASA) and the local Fernando Azevedo Correia Centre of Health. According to the human registered CL cases (2,025 from 2012-2018), most of them occurred in forested areas close to residences in rural areas. Brasiléia is characterised by human occupation associated with agricultural and extractive activities and intense deforestation. The increasing CL cases reported in the municipality suggests an adaptation of sandflies on the transmission of CL agents in the peridomicile environment situated very close to forest areas, where animal farming in proximity to houses is frequently observed.

Sandfly capture and morphological identification Sandflies were captured between September 2013 and January 2015 in seven areas situated in the rural zone (transversely positioned along the Federal BR 317 Trans Pacific Highway and identified as Ramal or Ramais, based on the distance in kilometres from the centre of

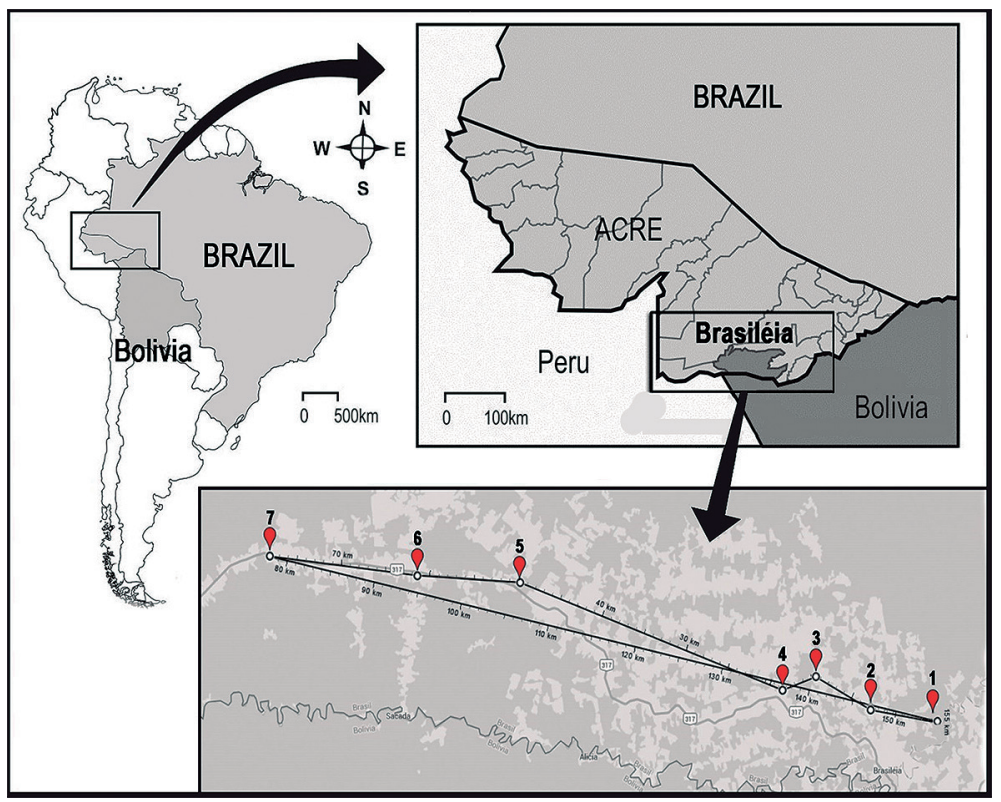

Municipality of Brasiléia, state of Acre, Brazil. The inset shows a satellite image indicating the distances between the seven study areas where sandflies were captured. Rural areas (located transversely along Trans Pacific Federal Highway BR 317): Area 1 - Kilometre 4, Ramal do Polo

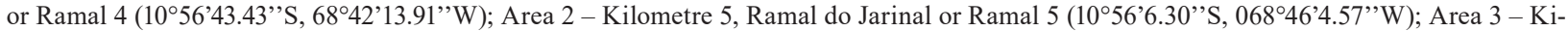

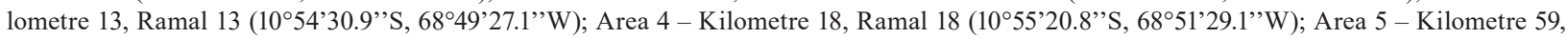

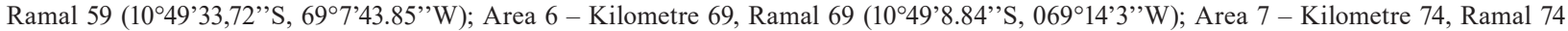
$\left(10^{\circ} 48^{\prime} 8.84^{\prime \prime} \mathrm{S}, 069^{\circ} 23^{\prime} 9,78^{\prime \prime} \mathrm{W}\right)$. 
Brasiléia) (Figure). The sites of capture were named by areas and Ramais, comprising areas of high-density forest (areas A1-R4, A3-R13, A4-R18, A5-R59) and peridomicile environment (areas A2-R5, A6-R69, A7-R74). The rural zone presents a dense forest in one side of the dirt road and most of the residences situated in the other side do not present basic services such as sanitation. The houses are surrounded by forest and the presence of several animals in the peridomicile can be observed, providing a favourable environment for the attraction of insect vectors and the occurrence of tropical diseases.

The selected areas were considered strategic for regular sandfly captures due to the high incidence of human $\mathrm{CL}$ cases in the neighbouring population. Captures were performed in private areas after receiving permission from the landowners. The sites of capture were georeferenced and the coordinates were obtained using a Global Positioning System (GPS) device. Sandfly captures were performed under a permanent license from the Biodiversity Authorisation and Information System (SISBIO) for the capture of zoological material (process 32669-4).

Sandflies were captured using light traps (HP model) placed at ground level (50-100 cm high) or at the top of trees (10-15 m high). In a first visit to recognise the areas, only ground level HP light traps were distributed in the peridomicile environments (areas A2-R5, A6-R69 and A7-R74) during $12 \mathrm{~h}(06: 00 \mathrm{pm}$ to $06: 00 \mathrm{am})$. For the dense forest areas (A1-R4, A3-R13, A4-R18 and A5-R59), light traps were positioned during $24 \mathrm{~h}$ (from $06: 00 \mathrm{pm}$ to 06:00 pm of the following day), at the ground and at the top of trees in the forested environment near the houses. In addition, to determine phlebotomine anthropophily, a modified Shannon trap (model in "T") with an attractive light was used from 06:00 pm to 09:00 pm under appropriate biosafety conditions [personal protective equipment (PPE)]. The strategy of captures is described in Table I.

Insects were stored in $80 \%$ ethanol and transported to the laboratory for preliminary screening and classification by area and strategy of capture. Males and females were clarified and diaphanised according to Forattini ${ }^{(11)}$ and identified following the taxonomic key proposed by Galati. ${ }^{(12,13)}$ The abbreviation of species names followed Marcondes. ${ }^{(14)}$ The mounting of female specimens on glass slides was performed using only the last abdominal segments and head for the microscopic observation of the genital tract and head structures (palps and cibarium); the thorax and abdomen were used for Leishmania DNA-detection, characterisation of the parasite species and blood gut-content analysis. Following species identification, each specimen was placed in a $1.5 \mathrm{~mL}$ tube and stored at $-20^{\circ} \mathrm{C}$ until DNA extraction.

Polymerase chain reaction (PCR) assays for the detection of Leishmania DNA - A sampling of sandfly females was random selected and individually analysed for the presence of Leishmania DNA. The genetic material of each specimen was extracted and submitted to a multiplex PCR assay following a previously established protocol. ${ }^{(15)}$ The assay is able to simultaneously amplify the conserved minicircle region of Leishmania kDNA (primer A: 5' GGC CCA CTA TAT TAC ACC AAC CCC 3'; primer B: 5' GGG GTA GGG GCG TTC TGC GAA 3') ${ }^{(16)}$ and the IVS6 region of the cacophony gene of neotropical sandflies (5Llcac: 5' GTG GCC GAA CAT AAT GTT AG 3'; 3Llcac: 5' CCA CGA ACA AGT TCA ACA TC $\left.3^{\prime}\right) ; ;^{(17)}$ this sequence served as an internal control for enzyme activity (by checking for the presence of potential inhibitors in the insect samples) and DNA yield and purity. ${ }^{(15)}$ Rigorous procedures were followed to control potential contamination. Male sandflies were included as negative controls for the DNA extraction step and all instruments and working areas were previously decontaminated with a diluted chloride solution and ultraviolet light. DNA extracts from Lu. longipalpis females that were artificially infected by feeding on rabbit blood (inactivated at $56^{\circ} \mathrm{C}$ ) containing $2 \times 10^{5}$ Leishmania (Viannia) braziliensis promastigotes $/ \mathrm{mL}$ and DNA purified from $L$. (V.) braziliensis promastigotes were used as positive controls.

Identification of Leishmania species in kDNA-positive sandfly samples - Parasite species identification in the positive sandfly samples was performed by PCR amplification of the Leishmania hsp70 (target, hsp70C reverse: 5' GGA CGA GAT CGA GCG CAT GGT 3' and hsp70C forward: 5' TCC TTC GAC GCC TCC TGG TTG 3'), generating a $234 \mathrm{bp}$ fragment, as previously described. ${ }^{(18)}$ The $234 \mathrm{bp}$ products were subjected to a second round of amplification using the hsp70C reverse primer and a new forward primer 5' (hsp70F2 GGA GAA CTA CGC GTA CTC GAT GAA G3'), ${ }^{(19)}$ which amplifies an internal 144 bp region of the Leishmania hsp 70 gene. The 144 bp products were cloned using $\mathrm{pGEM}^{\circledR}$-T Easy Vector Systems (Promega, Madison, USA) following the manufacturer's standard procedures. Recombinant plasmids containing the Leishmania DNA insert of each positive sandfly sample were subjected to DNA extraction using the commercial PureLink Quick Plasmid DNA Miniprep kit (Invitrogen, Carlsbad, USA), according to the manufacturer's protocol and submitted to sequencing.

Identification of blood meal sources in blood-fed sandfly females - The identification of blood gut-content of engorged sandfly females was conducted by PCR-based analysis of the cytochrome B gene (cyt b), using primers previously described, ${ }^{(20)}$ followed by sequencing the $383 \mathrm{bp}$ product. DNA extracted from male sandflies was used as negative control and DNA from Lu. longipalpis females previously fed on rabbit blood (inactivated at $56^{\circ} \mathrm{C}$ ) serves as positive control for the amplification reactions.

Sequencing - For both the analyses of Leishmania DNA-detection and food source, purified DNA or amplified PCR products respectively were submitted to sequencing. Reactions were performed using Big Dye Terminator v.3.1 Cycle Sequencing (Applied Biosystems Foster City, USA) following the manufacturer's specifications and assayed in the Sanger ABI 3730 Sequencing. Consensus sequences were obtained and edited using the software package Phred/Phrap/Consed version: 0.020425.c (University of Washington, Seattle, USA) and only those sequences with Phred values above 20 were used as contigs. The contigs were assembled and aligned in MEGA5 software ${ }^{(21)}$ and sequences were evaluated against NCBI $n r$ database using BLASTn. ${ }^{(22)}$ 


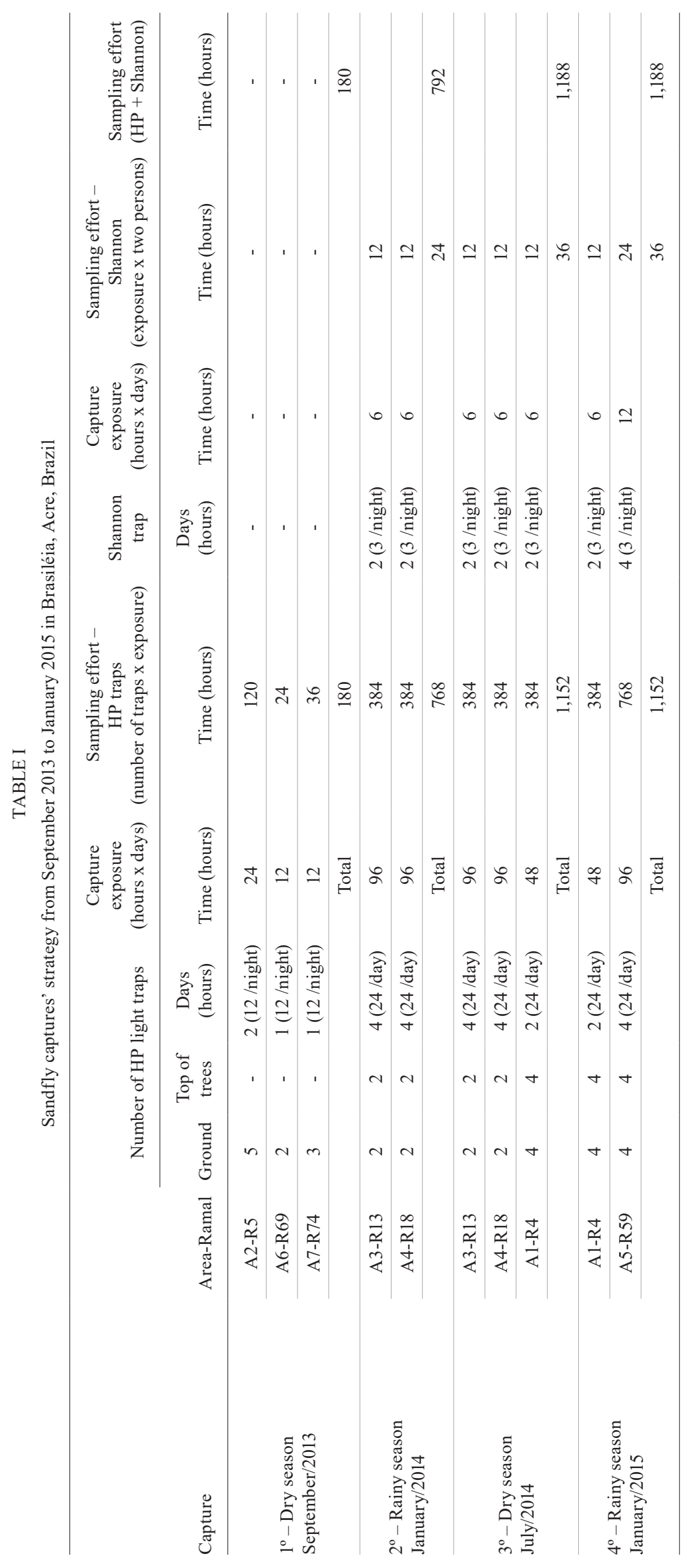


Data analysis - The measures of diversity among the environments were obtained using the ShannonWiener's $\left(H^{\prime}\right)$ diversity index, the Pielou's equitability index $(J$ '), Margalef 's richness index and the BergerParker's dominance index. ${ }^{(23)}$ Kruskal-Wallis was used to test the equality among the ecological descriptors in the different areas/environments. The male/female ratios were calculated by the chi-squared test $\left(\chi^{2}\right)$ and the comparison of the insect's averages by hour of capture in the rainy/dry seasons was performed by the Student's $t$ test. The analyses were carried out using the IBM SPSS 20 software, with a $5 \%$ level of significance.

Ethics - Access to genetic heritage has been registered into the National System for the Management of Genetic Heritage and Associated Traditional Knowledge (SisGen - A41DBDD).

\section{RESULTS}

Sandfly fauna - A total of 4,473 sandflies were captured being the proportion of female $(\mathrm{n}=2,297,51.35 \%)$ higher than that of male $(n=2,176,48.65 \%)\left[\chi^{2}=16.27\right.$; degrees of freedom $(\mathrm{df})=3 ; \mathrm{p}<0.05]$. Sixty-one species were identified belonging to 15 genera: Nyssomyia, Psychodopygus, Trichophoromyia, Lutzomyia, Evandromyia, Pintomyia, Psathyromyia, Bichromomyia, Pressatia, Brumptomyia, Viannamyia, Sciopemyia, Trichopygomyia, Micropygomyia and Migonemyia. The Nyssomyia genus was the most frequently captured $(41.12 \%$ of the total), followed by Psychodopygus (30.53\%) and Trichophoromyia (11.62\%) (Table II). The females identified as Trichophoromyia probably represent Th. octavioi and Th. auraensis, since up to now these species are not distinguishable. In the dense forest environment where the three methods of capture were applied (light traps near the ground and on the top of trees and Shannon trap), 4,389 specimens of 58 species were captured, whereas only 84 specimens belonging to 21 species were captured with light traps positioned near the ground in the peridomicile environment (Table II). Ny. shawi was the most frequent species ( $26.83 \%$ of the total) and occurred in all areas of forest environment, but it was not present in the captures in the peridomicile rural environment. The second more frequent was Ps. davisi (12.1\%), followed by Ps. carrerai (6.6\%), Nyssomyia sp. (5.9\%), Ny. whitmani (4.7\%) and Th. octavioi (4.6\%). The other species together represented $39.3 \%$ of the total captured specimens.

Captures were carried out in the dry and rainy seasons performing four capture campaigns (Table I). The first (2013 - dry season) was performed in areas A2-R5, A6-R69 and A7-R74, with a sampling effort of $180 \mathrm{~h} ; 84$ sandflies were trapped giving an average of 5.60 insects per trap. The second (2014 - rainy season) refers to areas A3-R13 and A4-R18, totalising $792 \mathrm{~h} ; 394$ specimens were captured with an average of 10.94 sandflies per trap. The third visit (2014 - dry season) contemplated areas A1-R4, A3-R13, A4-R18 with a sampling effort of

TABLE II

Abundance and distribution of sandflies captured from September 2013 to January 2015 in Brasiléia, Acre, Brazil

\begin{tabular}{|c|c|c|c|c|c|c|c|c|c|c|c|}
\hline \multirow[b]{2}{*}{ Genera } & \multirow[b]{2}{*}{ Species } & \multicolumn{4}{|c|}{ Forest environment } & \multirow[b]{2}{*}{$\mathrm{TF}$} & \multicolumn{3}{|c|}{ Peridomicile environment } & \multirow[b]{2}{*}{$\mathrm{TP}$} & \multirow[b]{2}{*}{ OP \% } \\
\hline & & A1R4 & A3R13 & A4R18 & A5R59 & & A2R5 & A6R69 & A7R74 & & \\
\hline \multirow{6}{*}{ Nyssomyia } & Ny. shawi & 823 & 89 & 34 & 254 & 1,200 & & & & & 26.83 \\
\hline & Ny. whitmani & 143 & 28 & 8 & 31 & 210 & & & & & 0.46 \\
\hline & Ny. antunesi & 72 & 74 & 19 & 28 & 193 & 6 & & & 6 & 4.45 \\
\hline & Ny. umbratilis & 8 & 68 & 42 & 3 & 121 & & & & & 2.57 \\
\hline & Ny. yuilli yuilli & 8 & 21 & 9 & 2 & 40 & & & & & 0.89 \\
\hline & Nyssomyia sp. & 164 & 28 & 32 & 27 & 251 & 14 & & & 14 & 5.92 \\
\hline \multirow{3}{*}{ Lutzomyia } & Lu. sherlocki & 22 & 36 & 38 & 5 & 101 & & & & & 2.26 \\
\hline & Lu. flabellata & 2 & & & 2 & 4 & & & & & 0.08 \\
\hline & Lutzomyia sp. & 11 & 34 & 7 & 0 & 52 & & & & & 1.16 \\
\hline \multirow{14}{*}{ Psychodopygus } & Ps. davisi & 276 & 115 & 32 & 119 & 542 & & & & & 12.12 \\
\hline & Ps. carrerai carrerai & 152 & 8 & 3 & 130 & 293 & & & & & 8.47 \\
\hline & Ps. llanosmartinsi & 4 & & & 163 & 167 & & & & & 6.55 \\
\hline & Ps. amazonensis & 27 & 12 & 13 & 46 & 98 & & & & & 2.19 \\
\hline & Ps. hirsutus hirsutus & 32 & 13 & 2 & 39 & 86 & & & & & 1.92 \\
\hline & Ps. paraensis & 6 & 10 & 10 & 25 & 51 & & & & & 1.14 \\
\hline & Ps. geniculatus & 6 & 2 & & 23 & 31 & & & & & 0.69 \\
\hline & Ps. lainsoni & 21 & & & 6 & 27 & & & & & 0.60 \\
\hline & Ps. chagasi & & & & 11 & 11 & & & & & 0.24 \\
\hline & Ps. claustrei & & & 1 & 2 & 3 & & 1 & & 1 & 0.08 \\
\hline & Ps. bispinosus & & & & 1 & 1 & & & & & 0.02 \\
\hline & Ps. complexus & 1 & & & & 1 & & & & & 0.02 \\
\hline & Ps. dorlinsis & & & & 1 & 1 & & & & & 0.02 \\
\hline & Psychodopygus sp. & 29 & 8 & 5 & 12 & 54 & & & & & 1.21 \\
\hline
\end{tabular}




\begin{tabular}{|c|c|c|c|c|c|c|c|c|c|c|c|}
\hline \multirow[b]{2}{*}{ Genera } & \multirow[b]{2}{*}{ Species } & \multicolumn{4}{|c|}{ Forest environment } & \multirow[b]{2}{*}{$\mathrm{TF}$} & \multicolumn{3}{|c|}{ Peridomicile environment } & \multirow[b]{2}{*}{$\mathrm{TP}$} & \multirow[b]{2}{*}{ OP $\%$} \\
\hline & & A1R4 & A3R13 & A4R18 & A5R59 & & A2R5 & A6R69 & A7R74 & & \\
\hline \multirow{2}{*}{ Trichopygomyia } & Ty. dasypodogeton & 1 & 2 & 3 & & 6 & & & & & 0.13 \\
\hline & Trichopygomyia sp. & & 3 & & 1 & 4 & & & & & 0.08 \\
\hline \multirow{5}{*}{ Trichophoromyia } & Th. octavioi & 47 & 18 & 22 & 118 & 205 & & & & & 4.58 \\
\hline & Th. auraensis & 47 & 3 & 8 & 54 & 112 & & 1 & 4 & 5 & 2.62 \\
\hline & Th. ubiquitalis & 5 & & & 2 & 7 & & & & & 0.15 \\
\hline & Th. clitella & 1 & & & & 1 & & & & & 0.02 \\
\hline & Trichophoromyia sp. & 25 & 7 & 19 & 139 & 190 & & & & & 4.25 \\
\hline \multirow{9}{*}{ Evandromyia } & Ev. saulensis & 4 & 13 & 40 & 4 & 61 & 4 & 5 & & 9 & 1.56 \\
\hline & Ev. bacula & 4 & & 2 & 2 & 8 & 1 & & & 1 & 0.08 \\
\hline & Ev. infraspinosa & & 1 & 3 & & 4 & 1 & & & 1 & 0.11 \\
\hline & Ev. termitophila & 1 & & 3 & & 4 & 1 & & & 1 & 0.11 \\
\hline & Ev. monstruosa & & 2 & 1 & & 3 & & & & & 0.06 \\
\hline & Ev. walkeri & & & 2 & & 2 & & & & & 0.04 \\
\hline & Ev. cortelezzii & & & & & & & 1 & & 1 & 0.02 \\
\hline & Ev. williamsi & & 2 & & & 2 & & & & & 0.04 \\
\hline & Evandromyia sp. & 1 & 7 & 9 & 1 & 18 & 8 & 4 & & 12 & 0.67 \\
\hline \multirow{3}{*}{ Pintomyia } & Pi. serrana & 29 & 10 & 11 & 11 & 61 & & & 1 & 1 & 1.39 \\
\hline & Pi. nevesi & 5 & 3 & 4 & 2 & 14 & 1 & 1 & & 2 & 0.35 \\
\hline & Pintomyia sp. & & 2 & & & 2 & 1 & & & 1 & 0.06 \\
\hline \multirow{4}{*}{ Bichromomyia } & Bi.flaviscutellata & 1 & 1 & 20 & & 22 & & & & & 0.51 \\
\hline & Bi. olmeca nociva & & 7 & 1 & & 8 & 1 & & & 1 & 0.20 \\
\hline & Bi. olmeca bicolor & & & & 2 & 2 & & & & & 0.04 \\
\hline & Bichromomyia sp. & & 2 & 1 & & 3 & & & & & 0.06 \\
\hline \multirow{10}{*}{ Psathyromyia } & Pa. aragaoi & 9 & 5 & 3 & 1 & 18 & 1 & & 1 & 2 & 0.44 \\
\hline & Pa. dendrophyla & 7 & & 2 & 3 & 12 & 1 & & & 1 & 0.29 \\
\hline & Pa. bigeniculata & & 5 & & & 5 & & & & & 0.11 \\
\hline & Pa. lutziana & & 3 & 1 & & 4 & 1 & & & 1 & 0.11 \\
\hline & Pa. abonnenci & 2 & & 1 & & 3 & & & & & 0.06 \\
\hline & Pa. campbelli & & 2 & 1 & & 3 & & & & & 0.06 \\
\hline & Pa. scaffi & 1 & 1 & & 1 & 3 & & & & & 0.06 \\
\hline & Pa. abunaensis & 1 & & & & 1 & & & & & 0.02 \\
\hline & Pa.punctigeniculata & & 1 & & & 1 & & & & & 0.02 \\
\hline & Psathyromyia sp. & 4 & 7 & 3 & 5 & 19 & 1 & & & 1 & 0.44 \\
\hline Viannamyia & Vi. furcata & 3 & 7 & 2 & & 12 & & & & & 0.26 \\
\hline \multirow{5}{*}{ Pressatia } & Pr. choti & 3 & & & & 3 & & & & & 0.06 \\
\hline & Pr. duncanae & 2 & 1 & & & 3 & & & & & 0.06 \\
\hline & Pr. calcarata & 1 & & & & 1 & & & & & 0.02 \\
\hline & Pr. triacantha & & & 1 & & 1 & & & & & 0.02 \\
\hline & Pressatia sp. & 7 & & 1 & & 8 & 2 & & & 2 & 0.22 \\
\hline \multirow{4}{*}{ Brumptomyia } & Br. galindoi & & & & 1 & 1 & & & & & 0.02 \\
\hline & Br. mangabeirai & & & 1 & & 1 & & & & & 0.02 \\
\hline & Br. avellari & & & & & & 8 & & & 8 & 0.17 \\
\hline & Brumptomyia sp. & & & & & & 5 & & & 5 & 0.11 \\
\hline \multirow{3}{*}{ Sciopemyia } & Sc. sordellii & & & & & & 2 & & 3 & 5 & 0.11 \\
\hline & Sc. servulolimai & & 1 & 2 & & 3 & & & & & 0.06 \\
\hline & Sciopemyia sp. & & 2 & 1 & & 3 & 1 & & & 1 & 0.08 \\
\hline Mïrnemvi & Mg. migonei & & & 1 & 1 & 2 & & & & & 0.04 \\
\hline Migonemyıа & Migonemyia sp. & & & 1 & & 1 & & & & & 0.02 \\
\hline & Mi. longipennis & 3 & & & & 3 & & & & & 0.06 \\
\hline & Mi. trinidadensis & 1 & & & & 1 & & & & & 0.02 \\
\hline Micropygomyia & Mi. micropyga & & & & & & 1 & & & 1 & 0.02 \\
\hline & Micropygomyia sp. & & & & & & 1 & & & 1 & 0.02 \\
\hline Total & & 2,022 & 664 & 425 & 1,278 & $4,389^{a}$ & 62 & 13 & 9 & $84^{a}$ & 100 \\
\hline
\end{tabular}

a: comparison for the abundance of sandflies in the forest and peridomicile environments. A: area; OP \%: overall percentage; R: Ramal (defined by the distance in kilometres along the Trans Pacific Federal Highway BR 317); TF: total forest environment; TP: total peridomicile environment. Kruskal-Wallis test. $H=36.6$, degrees of freedom $(\mathrm{df})=14, \mathrm{p}=0.001$. 
TABLE III

Ecological descriptors of sandflies captured from September 2013 to January 2015 in Brasiléia, Acre, Brazil

\begin{tabular}{lccccccc}
\hline & \multicolumn{3}{c}{ Forest environment } & \multicolumn{3}{c}{ Peridomicile environment } \\
\cline { 2 - 8 } Ecological descriptors & A1R4 & A3R13 & A4R18 & A5R59 & A2R5 & A6R69 & A7R74 \\
\hline Species richness (S') & 45 & 42 & 45 & 38 & 21 & 6 & 4 \\
\hline Shannon-Wiener index $\left(H^{\prime}\right)$ & $2.24^{a}$ & $2.90^{b}$ & $3.14^{a}$ & $2.61^{b}$ & 2.55 & 1.51 & 1.21 \\
\hline Pielou equitability $\left(J^{\prime}\right)$ & 0.59 & 0.77 & 0.82 & 0.72 & 0.83 & 0.84 & 0.87 \\
\hline Berger-Parker's index $\left(D^{\prime}\right)$ & 0.40 & 0.17 & 0.09 & 0.19 & 0.22 & 0.38 & 0.44 \\
\hline Dominant species per area & NS & PD & NU & NS & N & ES & TA \\
\hline
\end{tabular}

$a$ : comparison for the diversity index $\left(H^{\prime}\right)$ between A1R4 and A4R18 areas [Kruskal-Wallis test. $H=24.16$, degrees of freedom $(\mathrm{df})=14, \mathrm{p}=0.044]$; $b$ : comparison for the diversity index $\left(H^{\prime}\right)$ between A3R13 and A5R59 areas (Kruskal-Wallis test. $H=31.6$, $\mathrm{df}=14, \mathrm{p}=0.004)$. A: area; ES: Evandromyia saulensis; N: Nyssomyia sp.; NU: Nyssomyia umbratilis; PD: Psychodopygus davisi; R: Ramal (defined by the distance in kilometres along the Trans Pacific Federal Highway BR 317); NS: Nyssomyia shawi; TA: Trichophoromyia auraensis.

1,188 h; a total of 2,081 individuals was captured with an average of 38.53 insects per trap. The last capture (2015 - rainy season) was conducted in areas A1-R4 and A5R59 with a sampling effort of $1,188 \mathrm{~h}$; a total of 1,914 specimens was captured with an average of 35.44 sandflies per trap. All areas of the dense forest environment where the three methodologies of capture were applied (areas A1-R4, A3-R13, A4-R18 and A5-R59) presented identical sampling effort (792 $\mathrm{h}$ each). Of the total of 4,473 individuals, $51.6 \%(\mathrm{n}=2,308)$ were captured in the rainy season with a sampling effort of $1,980 \mathrm{~h}$ and an average of 1.16 individuals trapped per hour, whereas $48.4 \%$ of the total $(n=2,165)$ were captured in the dry season with a sampling effort of $1,368 \mathrm{~h}$ and an average of 1.58 individuals trapped per hour $(\mathrm{p}=0,053, \mathrm{df}=4)$.

Relative to all studied areas of both forest and domicile environments, the most frequent species in the light traps located at the top of trees were $N y$. shawi $(27.5 \%$, $\mathrm{n}=499)$, Ps. davisi $(13.1 \%, \mathrm{n}=239), N y$. antunesi $(6.6 \%$, $\mathrm{n}=120)$, Ps. llanosmartinsi $(6.5 \%, \mathrm{n}=118)$, Ps. carrerai $(6 \%, \mathrm{n}=109)$ and $N y$. whitmani $(6 \%, \mathrm{n}=109)$. In the light traps near the ground, the most frequent species were Th. octavioi $(13.5 \%, \mathrm{n}=178), N y$. shawi $(11.8 \%, \mathrm{n}$ $=156)$, Trichophoromyia sp. $(11.3 \%, \mathrm{n}=149)$ and Ps. davisi $(9.7 \%, \mathrm{n}=128)$. In Shannon traps, $N y$. shawi $(40.4 \%$, $\mathrm{n}=545)$ was the most frequently captured species, followed by Ps. davisi (13\%, $\mathrm{n}=175)$, Ps. carrerai $(11.2 \%$, $\mathrm{n}=152)$, Nyssomyia sp. $(7.1 \%, \mathrm{n}=96)$, Ny. whitmani $(5.2 \%, \mathrm{n}=70)$ and $L u$. sherlocki $(3.8 \%, \mathrm{n}=52)$. The other specimens together $(19 \%, \mathrm{n}=256)$ make up the total of 1,346 sandflies captured in Shannon.

Considering only the dense forest environment with three methodologies of captures, the average numbers of sandflies per trap were 19.2, 28.3 and 84.1, respectively to HP light traps near the ground, on the top of trees and Shannon. In Shannon and light traps, $N y$. shawi was the most captured species and area A1-R4 was the one with the highest number of specimens of the Nyssomyia genus. In the dense forest areas, 4,389 individuals were captured with the most abundant being Ny. shawi, Ps. davisi, Ny. umbratilis, Ev. saulensis, Th. auraensis and Nyssomyia sp.
In the forest environment, area A1-R4, the diversity (Shannon index, $\left.H^{\prime}\right)$ of species was $2.24(\mathrm{~S}=45)$ and equitability $(J$ ') was 0.59 , whereas in area A4-R18 the diversity was higher at $3.14(\mathrm{~S}=45)$ and equitability was also higher $\left(J^{\prime}=0.82\right)$, demonstrating a more uniform pattern of species frequencies (Table III). Although both the areas present the same number of species, the number of individuals in area A4-R18 is much lower (A1-R4, $\mathrm{n}=2,022$ and A4-R18, $\mathrm{n}=425$ ) (Table II), despite the higher diversity of species in this area $(H=24.16, \mathrm{df}=$ $14, p=0,044)$. The other areas comprising the forest environment (A3-R13 and A5-R59) revealed diversity indexes of $2.90(\mathrm{~S}=42)$ and $2.61(\mathrm{~S}=38)$, and equitability $\left(J^{\prime}\right) 0.77$ and 0.72 , respectively. These results demonstrate a relatively minor balance for area A5-R59 compared to A3-R13 $(H=3.6, \mathrm{df}=14, \mathrm{p}>0.004)$. Species dominance, according to the Berger-Parker's index, varied from 0.09 to 0.44 for both, forest and peridomicile environments. Only one area of the peridomicile environment (A2-R5) shows diversity index similar to the ones observed in the forest areas at $2.55(\mathrm{~S}=21)$, but with a lower number of species. Higher equitability values $\left(J^{\prime}\right)$ were observed in the peridomicile environment, varying between 0.83 to 0.87 (Table III).

Leishmania DNA-detection in non-blood-fed female sandflies - A panel of 864 female sandflies without blood in their guts was analysed for the presence of Leishmania DNA (Table IV). Engorged sandflies were excluded from the detection assays due to the possibility of detecting occasional ingestion of blood from an infected source. In 25 individuals, positive results were observed by kDNA-PCR in agarose gels, corresponding to a $2.9 \%$ detection rate in the study area. The sandfly species of positive samples are indicated in Table $\mathrm{V}$ and these specimens were captured in all areas of forest environment and in only one peridomicile area (A2-R5). Leishmania DNA positive sandflies were captured in all four capture campaigns. Positive insects were not identified in area A6-R69, while the few specimens captured in area A7-R74 presented blood in their gut contents and were not subjected to the diagnosis of Leishmania spp. detection. 
TABLE IV

Sandflies analysed for the presence of Leishmania DNA (non-blood-fed females)

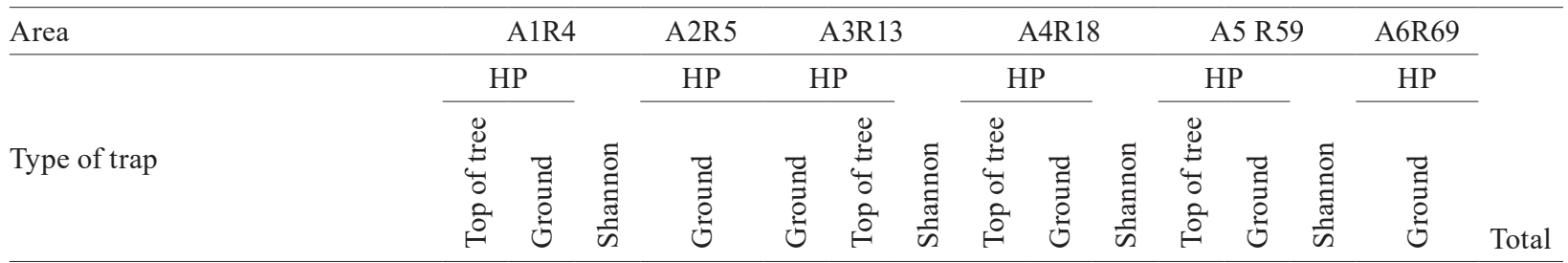

Species

\begin{tabular}{|c|c|c|c|c|c|c|c|c|c|c|c|c|c|c|c|}
\hline Nyssomyia shawi & 21 & 21 & 44 & & 34 & 14 & 5 & 1 & 4 & 10 & 9 & 4 & 13 & & 180 \\
\hline Nyssomyia sp. & 19 & 28 & 5 & 11 & 16 & 6 & 4 & 3 & 9 & 19 & 6 & 9 & 9 & & 144 \\
\hline Trichophoromyia sp. & 6 & 11 & 1 & & & 4 & & & 14 & 2 & 15 & 22 & 3 & & 78 \\
\hline Psychodopygus davisi & 13 & 12 & 14 & & 5 & 5 & 6 & 2 & 1 & 7 & 1 & & 4 & & 70 \\
\hline Nyssomyia umbratilis & & 4 & & & 6 & 3 & 3 & 20 & 6 & & 1 & 1 & & & 44 \\
\hline Psychodopygus carrerai & 3 & 3 & 18 & & 1 & 1 & 1 & & & 1 & 2 & 4 & 8 & & 42 \\
\hline Evandromyia saulensis & & 2 & & & 1 & 5 & 1 & & 18 & 5 & & & & 4 & 36 \\
\hline Psychodopygus sp. & 7 & & 6 & & 2 & 3 & 3 & 1 & 1 & 3 & 4 & 3 & 1 & & 34 \\
\hline Psychodopygus amazonensis & 4 & & 2 & & 1 & 3 & 2 & & 1 & 8 & 3 & & 6 & & 30 \\
\hline Evandromyia sp. & & & & 7 & 2 & 4 & & & 5 & 2 & & & & 4 & 24 \\
\hline Lutzomyia sherlocki & & & & & 1 & 1 & 3 & 1 & & 14 & & & & & 20 \\
\hline Nyssomyia antunesi & 1 & & 2 & 1 & 7 & 2 & 2 & & 1 & 3 & & & & & 19 \\
\hline Nyssomyia yuilli yuilli & & & & & 11 & 1 & 1 & 4 & 1 & & & & & & 18 \\
\hline Psychodopygus hirsutus hirsutus & 7 & 1 & 3 & & 1 & & 1 & & & 2 & 2 & & & & 17 \\
\hline Psathyromyia sp. & 3 & & & 1 & 2 & & & & 2 & & 3 & 2 & & & 13 \\
\hline Lutzomyia sp. & 2 & & & & & & 7 & & & 3 & & & & & 12 \\
\hline Nyssomyia whitmani & 5 & 6 & & & & & & 1 & & & & & & & 12 \\
\hline Psychodopygus paraensis & & & & & 1 & & & & & 10 & & & & & 11 \\
\hline Pintomyia serrana & & & 1 & & 1 & & & 2 & 1 & 3 & & & & & 8 \\
\hline Psychodopygus lainsoni & 3 & 3 & 1 & & & & & & & & & & & & 7 \\
\hline Psychodopygus llanosmartinsi & & & & & & & & & & & 1 & & 6 & & 7 \\
\hline Brumptomyia sp. & & & & 5 & & & & & & & & & & & 5 \\
\hline Pintomyia nevesi & & & & 1 & & 3 & & & 1 & & & & & & 5 \\
\hline Psychodopygus geniculatus & 1 & & & & & & 1 & & & & 3 & & & & 5 \\
\hline Pressatia sp. & & 1 & & 2 & & & & 1 & & & & & & & 4 \\
\hline Pintomyia $\mathrm{sp}$. & & & & 1 & & 2 & & & & & & & & & 3 \\
\hline Sciopemyia sp. & & & & 1 & 1 & 1 & & & & & & & & & 3 \\
\hline Evandromyia bacula & & 1 & & 1 & & & & & & & & & & & 2 \\
\hline Psathyromyia dendrophyla & & & & 1 & & & & & 1 & & & & & & 2 \\
\hline Trichopygomyia dasypodogeton & & & & & & & & 2 & & & & & & & 2 \\
\hline Bichromomyia flaviscutellata & & & & & & & & & & 1 & & & & & 1 \\
\hline Evandromyia monstruosa & & & & & & & & & & 1 & & & & & 1 \\
\hline Evandromyia termitophila & & & & 1 & & & & & & & & & & & 1 \\
\hline Psathyromyia bigeniculata & & & & & 1 & & & & & & & & & & 1 \\
\hline Psathyromyia lutziana & & & & & & 1 & & & & & & & & & 1 \\
\hline Psychodopygus complexus & & & 1 & & & & & & & & & & & & 1 \\
\hline Viannamyia furcata & & & & & & & & 1 & & & & & & & 1 \\
\hline Total & 95 & 93 & 98 & 33 & 94 & 59 & 40 & 39 & 66 & 94 & 50 & 45 & 50 & 8 & 864 \\
\hline
\end{tabular}

R: Ramal (defined by the distance in kilometres along the Trans Pacific Federal Highway BR 317). 
TABLE V

Female sandfly species with positive results for Leishmania spp. kDNA according to the area of capture, trap and the identified Leishmania species

\begin{tabular}{|c|c|c|c|c|c|c|}
\hline \multirow[b]{2}{*}{$\begin{array}{l}\text { Positive sandflies for } \\
\text { Leishmania kDNA }\end{array}$} & \multirow[b]{2}{*}{ Area-R/Trap } & \multirow[b]{2}{*}{$\begin{array}{c}\text { Parasite species } \\
(h s p 70)\end{array}$} & \multirow[b]{2}{*}{ Accession number } & \multicolumn{2}{|c|}{ BLAST analysis } & \multirow[b]{2}{*}{ Total } \\
\hline & & & & E-value & $\begin{array}{l}\text { Identity } \\
(\%)\end{array}$ & \\
\hline Brumptomyia sp. & A2-R5/HP ground & L. (V.) braziliensis & GU368187.1 & $8 e-62$ & 99 & 1 \\
\hline Evandromyia termitophila & A2-R5/HP ground & L. (V.) braziliensis & GU368187.1 & $8 \mathrm{e}-67$ & 100 & 1 \\
\hline Nyssomyia antunesi & A2-R5/HP ground & L. (V.) braziliensis & GU368187.1 & $8 \mathrm{e}-68$ & 100 & 1 \\
\hline \multirow{4}{*}{ Nyssomyia shawi } & A3-R13/HP tree & L. (V.) braziliensis & XM_0011566273.2 & $5 e-69$ & 100 & 1 \\
\hline & A1-R4/HP tree & L. (V.) guyanensis & FN395051.1 & $5 e-69$ & 100 & 1 \\
\hline & \multirow{2}{*}{ A1-R4/Shannon } & L. (V.) braziliensis & GU368187.1 & $5 e-69$ & 100 & 1 \\
\hline & & NI & & - & - & 1 \\
\hline Nyssomyia sp. & A5-R59/HP tree & NI & & - & - & 1 \\
\hline Nyssomyia umbratilis & A3-R13/HP tree & L. (V.) braziliensis & XM_001566273.2 & $2 \mathrm{e}-42$ & 89 & 1 \\
\hline Nyssomyia whitmani & A1-R4/HP tree & NI & & - & - & 1 \\
\hline Pintomyia nevesi & A2-R5/HP ground & L. (V.) braziliensis & XM_001566273.2 & $2 \mathrm{e}-42$ & 89 & 1 \\
\hline Pintomyia sp. & A2-R5/HP ground & NI & & - & - & 1 \\
\hline Psathyromyia sp. & A2-R5/HP ground & L. (V.) braziliensis & XM_001566273.2 & $1 e-65$ & 100 & 1 \\
\hline Psychodopygus amazonensis & A5-R59/Shannon & NI & & - & - & 1 \\
\hline \multirow{6}{*}{ Psychodopygus davisi } & A3R13/HP ground & L. (V.) braziliensis & LN907833.1 & $3 e-25$ & 97 & 1 \\
\hline & \multirow{3}{*}{ A4-R18/Shannon } & L. (V.) braziliensis & LN907845.1 & $5 e-39$ & 89 & 1 \\
\hline & & L. (V.) braziliensis & XM_001566273.2 & $1 e-65$ & 100 & 1 \\
\hline & & L. (V.) braziliensis & GU368187.1 & $3 e-25$ & 97 & 1 \\
\hline & A1-R4/Shannon & NI & & - & - & 2 \\
\hline & A5-R59/Shannon & NI & & - & - & 1 \\
\hline Psychodopygus hirsutus hirsutus & A4-R18/Shannon & L. (V.) braziliensis & LN907833.1 & $3 e-25$ & 97 & 1 \\
\hline \multirow{2}{*}{ Psychodopygus sp. } & A1-R4/HP tree & NI & & - & - & 1 \\
\hline & A1-R4/Shannon & L. (V.) guyanensis & GU368213.1 & $5 e-69$ & 100 & 1 \\
\hline Trichophoromyia sp. & A1-R4/HP ground & L. (V.) braziliensis & LN907845.1 & $3 e-25$ & 97 & 1 \\
\hline Total & & & & & & 25 \\
\hline
\end{tabular}

NI: not identified; R: Ramal (defined by the distance in kilometres along the Trans Pacific Federal Highway BR 317).

The positivity for Leishmania DNA per sandfly species was distributed as follows: $0.69 \%$ in Nyssomyia sp. (one/144); 1.28\% in Trichophoromyia sp. (one/78); $2.22 \%$ in $N y$. shawi (four/180); $2.27 \%$ in $N y$. umbratilis (one/44); $3.33 \%$ in Ps. amazonensis (one/30); 5.26\% in $N y$. antunesi (one/19); 5.88\% in Ps. hirsutus (one/17); $5.88 \%$ in Psychodopygus sp. (two/34); 7.69\% in Psathyromyia sp. (one/13); $8.33 \%$ in $N y$. whitmani (one/12); $10 \%$ in Ps. davisi (seven/70); 20\% in Brumptomyia sp. (one/5) and Pi. nevesi (one/5); 33.33\% in Pintomyia sp. (one/3) and $100 \%$ detection found in Ev. termitophila (one/one) (Table V).

The 25 positive samples were further analysed by hsp70-PCR and sequencing and in 16 of these samples $(64 \%)$ it was possible to identify the Leishmania species. BLAST analysis revealed the presence of $L$. (V.) brazili- ensis DNA with $100 \%$ identity for the species Ev. termitophila $(\mathrm{n}=1), N y$. antunesi $(\mathrm{n}=1), N y$. shawi $(\mathrm{n}=2)$, Psathyromyia sp. $(\mathrm{n}=1)$ and Ps. davisi $(\mathrm{n}=1)$. The other positive samples for $L$. (V.) braziliensis presented identity values between 89 and $99 \%$ and included females of Brumptomyia sp. $(\mathrm{n}=1), N y$. umbratilis $(\mathrm{n}=1), P i$. nevesi $(\mathrm{n}=1)$, Ps. davisi $(\mathrm{n}=3)$, Ps. hirsutus hirsutus $(\mathrm{n}=1)$ and Trichophoromyia $\mathrm{sp} .(\mathrm{n}=1)$. In two species, Ny. shawi $(\mathrm{n}=1)$ and Psychodopygus sp. $(\mathrm{n}=1)$, it was possible to confirm infection by $L$. (V.) guyanensis with $100 \%$ identity (Table V).

Blood meal and Leishmania DNA-detection in engorged female sandflies - A panel of 96 female sandflies containing traces of blood meal observed under of a stereomicroscope was subjected to food source analysis after being tested for Leishmania DNA, with the aim 
of identifying potential reservoirs affecting the parasite transmission cycle(s) in the studied areas. Thirteen species of mammals were identified in 39 out of the 96 samples (40.6\%): $41.02 \%(16 / 39)$ of these sequences corresponded to Homo sapiens; $10.26 \%$ (four/39) to each of Dasypus novemcinctus and Tamandua tetradactyla; $7.70 \%$ (three/39) to each of Coendou prehensilis and Sus scrofa; $5.13 \%$ (two/39) to Bos taurus; and 2.56\% (one/39) to each of Agouti paca, Choloepus didactylus, Dasyprocta fuliginosa, Dasypus kappleri, Didelphis marsupialis, Marmosops noctivagus and Pecari tajacu (Table VI). The remaining samples were left without feeding source identification due to the lack of similarity with those available sequences in the database or to the yield of low-quality sequences.

Among the 96 females analysed for the presence of Leishmania kDNA in the blood meal, to assess infection at the food source, 9.4\% (nine/96) showed positive results in agarose gels and were subjected to the identification of the parasite species using the $h s p 70$ target of Leishmania. The analysis of the amplified sequences revealed samples with $100 \%$ identity to $L$. (V.) shawi, $L$. (V.) braziliensis and $L$. (V.) guyanensis (Table VII). The sample harbouring $L$. (V.) guyanensis was a female of Sc. sordellii that had fed on H. sapiens and was captured in light trap near the ground in area A7-R74. Leishmania (V.) shawi and $L$. (V.) braziliensis were identified in Pa. aragaoi and Psathyromyia sp., respectively; the cyt $b$ analysis was not able to identify the food source in either sample.

The presence of Endotrypanum parasites was confirmed in females of Ny. umbratilis, Pa. aragaoi and Ps. davisi. For the last species, correlation with the probable mammalian host was only possible in the blood supply of one of the females, captured in light trap at the top of tree in area A1-R4, where the arboreal species C. prehensilis was identified (Table VII).

\section{DISCUSSION}

In the present study, of the 61 sandfly species captured in Brasiléia municipality, bordering Bolivia, five of them were recorded for the first time in the state of Acre: Bi. olmeca nociva, Br. galindoi, Br. mangabeirai, Ps. dorlinsis and Th. clitella. In addition, this investigation provides the first report of $P$ s. dorlinsis in the country, despite one solely male individual has been captured in light trap on top of tree in area A5-R59 of the forest environment. Of a total of 4,473 captured specimens, the dominance of species from Nyssomyia and Psychodopygus genera (76.4\% of the captures) is consistent with previous studies carried out in Acre. ${ }^{(7,24-27)}$ Both the genera are the most medically important in the New World, represent the most abundant species and concentrate several vector species of Leishmania, including the most important vectors incriminated in the transmission cycle of $\mathrm{CL}$ in the Amazon Region. ${ }^{(3,24,28)}$

Here, the most frequent species were $N y$. shawi (26.82\%), Ps. davisi (12.11\%) and Ps. carrerai (6.55\%). In relation to the last two species, our data corroborate prior studies in three municipalities of the state of Acre, where these were found at frequencies of 13.35 and $6.53 \%$, respectively. ${ }^{(24)}$ The genus Psychodopygus was the most dominant in Rio Branco, being Ps. carrerai and Ps. davisi the most abundant species. ${ }^{(29)}$ Although Ps. $d a-$ visi is often being found in peridomicile ecotopes, suggesting its adaptation to anthropic environments, in our study this species has not been captured in the peridomicile areas using light traps positioned near the ground. In Assis Brasil, Ps. davisi was captured at a frequency of $21.07 \%$ and Ps. carrerai carrerai represented $0.63 \%$ of the total specimens. ${ }^{(26)}$

Relative to the highest abundance of $N y$. shawi in our investigation, Teles et al. ${ }^{(26)}$ showed this species representing only $2.7 \%$ of the sandflies captured in Assis Brasil, and authors discuss the potential of $N y$. shawi as a vector of Leishmania parasites in this locality, which forms a three-border area with Peru and Bolivia. Azevedo et al. ${ }^{(24)}$ identified $N y$. shawi even less frequently $(0.85 \%)$ in Acre state, and in Rio Branco its frequency was even lower $(0.28 \%){ }^{(29)}$ Brilhante et al. ${ }^{(27)}$ reported the species Ps. carrerai carrerai (42\%), Ny. shawi (36\%) and Ps. davisi (13\%) as the most abundant in Xapuri. In our work, these three species were also the most abundant in Shannon traps; despite the use of light attraction, the human presence during capture may bias the attraction of these anthropophilic species, considering that all three are implicated as vectors of Leishmania spp. ( $N y$. shawi and Ps. carrerai carrerai act as potential vectors in Bolivia, and Ps. davisi as a potential vector in the Amazon Region of Brazil). ${ }^{(27,30-33)}$

The absolute abundance of $N y$. shawi and Ps. davisi (1,200 and 542 individuals, respectively) in our study, in which these species cohabit the forested ecotope, suggests their important roles in the transmission of CL agents in Brasiléia. It is important to mention that the high frequency of specimens of both Nyssomyia and Psychodopygus genera occur in the dense forest environments (45.91 and 31.12\%, respectively), with lower frequencies in the peridomicile (23.81 and $1.19 \%$, respectively); despite Nyssomyia genus be represented as the second more frequent in the peridomicile captures after the most dominant Evandromyia (29.76\%). The peridomicile areas, with only 84 specimens, present lower species richness, lower diversity (except for area A2-R5), with higher indexes of equitability, and two of three areas (A6-R69 and A7-R74) exhibit high species dominance (Ev. saulensis and Th. auraensis, respectively). The dense forest areas, performing $98 \%$ of the total of captures, present higher species richness, higher diversity (being area A4-R18 the one with the highest diversity index), with lower index of equitability (except of area A4-R18 with equitability similar to that of sampled areas in the peridomicile), and high species dominance could only be observed in area A1-R4 (Ny. shawi). The overall higher abundance and species richness in the forest environment were expected, if one considers the higher frequency of sandflies in non-degraded environments such as the high-density forest, in association with a greater sampling effort applied in these forested areas where the three methodologies of capture were used, compared to the peridomicile areas (only light traps on the ground). The captures with Shannon revealed the highest sandflies average followed by light traps positioned on the top of trees (84.1 and 28.3, 
TABLE VI

Consolidated analysis of blood gut-contents in sandflies

\begin{tabular}{|c|c|c|c|c|c|c|}
\hline \multirow[b]{2}{*}{ Species } & \multirow[b]{2}{*}{ Blood meal (cyt b) } & \multirow[b]{2}{*}{$\begin{array}{l}\text { Accession } \\
\text { number }\end{array}$} & \multicolumn{2}{|c|}{ BLAST analysis } & \multirow[b]{2}{*}{ Area-R/trap } & \multirow[b]{2}{*}{ Tota } \\
\hline & & & E-value & $\begin{array}{c}\text { Identity } \\
(\%)\end{array}$ & & \\
\hline Bichromomyia olmeca nociva & Bos taurus & KU891850.1 & $9 e-35$ & 86 & A3-R13/HP ground & 1 \\
\hline \multirow{3}{*}{ Evandromyia saulensis } & Homo sapiens & DQ489515.1 & $6 e-18$ & 92 & A3-R13/HP ground & 1 \\
\hline & Homo sapiens & KP126161.1 & $2 \mathrm{e}-161$ & 98 & A4-R18/HP ground & 1 \\
\hline & Sus scrofa & GQ338965.1 & $1 e-42$ & 91 & A3-R13/HP ground & 1 \\
\hline Evandromyia sp. & Tamandua tetradactyla & AF232019.1 & $2 \mathrm{e}-152$ & 98 & A2-R5/HP ground & 1 \\
\hline \multirow{2}{*}{ Lutzomyia sherlocki } & Homo sapiens & KM986625.1 & $9 e-68$ & 93 & A1-R4/HP tree & 1 \\
\hline & Sus scrofa & KJ652503.1 & $1 \mathrm{e}-17$ & 95 & A3-R13/HP ground & 1 \\
\hline \multirow{2}{*}{ Nyssomyia shawi } & Homo sapiens & KJ185819.1 & $2 \mathrm{e}-75$ & 89 & A4-R18/HP tree & 1 \\
\hline & Homo sapiens & KC622257.1 & $5 e-137$ & 99 & A1-R4/Shannon & 1 \\
\hline \multirow{2}{*}{ Nyssomyia sp. } & Homo sapiens & КТ779190.1 & $3 e-94$ & 87 & \multirow{2}{*}{ A2-R5/HP ground } & \multirow{2}{*}{2} \\
\hline & Homo sapiens & KR712115.1 & $6 e-73$ & 84 & & \\
\hline Pintomyia nevesi & Homo sapiens & KT897693.1 & $8 \mathrm{e}-140$ & 95 & A4-R18/Shannon & 1 \\
\hline \multirow{3}{*}{ Pintomyia serrana } & Agouti paca & AY206572.1 & $2 \mathrm{e}-72$ & 83 & A5-R59/HP ground & 1 \\
\hline & Coendou prehensilis & KC463874.1 & $4 e-163$ & 100 & A4-R18/HP tree & 1 \\
\hline & Homo sapiens & KP126161.1 & $8 \mathrm{e}-165$ & 99 & A1-R4/HP ground & 1 \\
\hline Psathyromyia aragaoi & Homo sapiens & KP126162.1 & 1e-163 & 99 & A3-R13/Shannon & 1 \\
\hline Psathyromyia sp. & Tamandua tetradactyla & KT818552.1 & $5 e-162$ & 99 & A4-R18/HP ground & 1 \\
\hline Psychodopygus amazonensis & Tamandua tetradactyla & KT818552.1 & $1 e-95$ & 99 & A5-R59/HP tree & 1 \\
\hline \multirow{5}{*}{ Psychodopygus carrerai carrerai } & Dasypus novemcinctus & AF493838.1 & $5 e-86$ & 91 & A1-R4/HP ground & 1 \\
\hline & Dasypus novemcinctus & KF799995.1 & 1e-108 & 89 & A1-R4/HP tree & 1 \\
\hline & Dasypus novemcinctus & KU253494.1 & $6 e-100$ & 96 & \multirow{2}{*}{ A5-R59/HP tree } & \multirow{2}{*}{2} \\
\hline & Dasypus novemcinctus & KU253494.1 & $6 e-115$ & 99 & & \\
\hline & Homo sapiens & KX365160.1 & $6 e-136$ & 97 & A5-R59/Shannon & 1 \\
\hline \multirow{8}{*}{ Psychodopygus davisi } & Coendou prehensilis & KC463874.1 & $8 \mathrm{e}-150$ & 98 & A1-R4/HP tree & 1 \\
\hline & Coendou prehensilis & KC463878.1 & $2 \mathrm{e}-57$ & 95 & A1-R4/HP ground & 1 \\
\hline & Dasyprocta fuliginosa & AF437784.1 & $1 e-107$ & 96 & A4-R18/HP ground & 1 \\
\hline & Dasypus kappleri & KT818541.1 & $2 \mathrm{e}-105$ & 89 & A1-R4/HP ground & 1 \\
\hline & Didelphis marsupialis & KJ129895.1 & $2 \mathrm{e}-32$ & 97 & A3-R13/HP tree & 1 \\
\hline & Marmosops noctivagus & KT437714.1 & $5 e-16$ & 77 & A3-R13/HP ground & 1 \\
\hline & Pecari tajacu & JN632683.1 & $7 e-116$ & 91 & A5-R59/Shannon & 1 \\
\hline & Tamandua tetradactyla & KT818552.1 & $7 e-42$ & 91 & A3-R13/Shannon & 1 \\
\hline Psychodopygus hirsutus hirsutus & Bos taurus & KT343749.1 & $2 e-33$ & 92 & A3- R13/HP tree & 1 \\
\hline Psychodopygus llanosmartinsi & Homo sapiens & KP126162.1 & $5 e-142$ & 96 & A5-R59/HP tree & 1 \\
\hline Psychodopygus sp. & Homo sapiens & KX690094.1 & $3 e-45$ & 97 & A5-R59/HP tree & 1 \\
\hline Sciopemyia servulolimai & Sus scrofa & KJ652503.1 & $1 e-157$ & 99 & A3-R13/HP ground & 1 \\
\hline Sciopemyia sordellii & Homo sapiens & KP126161.1 & $8 e-155$ & 97 & A7-R74/HP ground & 1 \\
\hline \multirow{2}{*}{ Trichophoromyia sp. } & Homo sapiens & KX697544.1 & $2 \mathrm{e}-166$ & 100 & A3-R13/HP tree & 1 \\
\hline & Homo sapiens & DQ489515.1 & $6 e-18$ & 92 & A3-R13/HP ground & 1 \\
\hline Trichopygomyia sp. & Choloepus didactylus & KR336792.1 & $1 e-128$ & 93 & A5-R59/HP ground & 1 \\
\hline Total & & & & & & 39 \\
\hline
\end{tabular}

R: Ramal (defined by the distance in kilometres along the Trans Pacific Federal Highway BR 317). 
respectively), being $N y$. shawi the most captured species in these traps, thus demonstrating a dominant behaviour in the dense forest environment and indicating the anthropophilic behaviour of this species.

Despite the human occupation and intense deforestation in Brasiléia, these areas of remaining forest suffer less anthropic impacts than that of the peridomicile environment, and consequently contribute in maintaining the higher richness on species distribution. Taking into account the original wild behaviour of sandflies, the distribution and species abundance are directly influenced by forested areas, as stated in a study on sandfly faunal diversity in southern Brazil, where a correlation between insects' richness and the existence of remaining forests was observed. ${ }^{(34)}$ As previously reported and corroborating with the data here obtained, high species diversity is frequently found in the Amazon Region. ${ }^{(33,35,36)}$

Studies on Leishmania infection/detection in sandflies contribute with functional indicators of the parasite transmission intensity in endemic areas. In this context, the search for Leishmania DNA in the sandfly fauna of Brasiléia could suggests the implication of positive species as potential vectors of CL agents in the sampled areas, being that the first essential criterion to be regarded as suspected vectors. ${ }^{(37)}$ Here, we found 25 positive specimens out of 864 females individually analysed in the evaluation of possible natural infections, corresponding to a detection rate of $2.9 \%$ for Leishmania spp. The positive specimens were trapped in all areas of forest environment and only in one area of peridomicile (A2-R5). The minor sampling efforts for the peridomicile environment resulted in few specimens captured and a minor chance of finding positive sandflies. Our results revealed the circulation of $L$. (V.) braziliensis and $L$. (V.) guyanensis in Brasiléia, the second municipality in the state of Acre with the highest number of notifications of human cases of CL; in the period 2012 to 2017, the Rio Branco and Brasiléia notified 2,652 and 2,025 cases, respectively.

Relative to the higher number of specimens submitted to Leishmania DNA-detection, Ps. davisi represented the species with the highest positivity (seven/70,10\%) for $L$. (V.) braziliensis. All positive specimens were captured in the forest environment, six of them in Shannon and one in light trap positioned on the ground. Other studies in the Amazon Region point to Ps. davisi as a putative vector of $L$. (V.) braziliensis and $L$. (V.) naiffi in the states of Rondônia ${ }^{(35,38)}$ and Pará ${ }^{(39)}$ respectively. Despite its wild habitat, as observed in the present work and also in Rio Branco, ${ }^{(29)}$ Ps. davisi has been frequently found in peridomestic environments associated to the occurrence of $\mathrm{CL}$, suggesting its adaptation to anthropic environments. (29,40) In the municipality of Assis Brasil, this species was found to be DNA positive for both $L$. (V.) braziliensis and L. (V.) guyanensis. ${ }^{(26)}$ In Rio Branco, Ps. davisi was one of the most abundant species and $L$. $(V$. ) braziliensis was identified in one solely individual. ${ }^{(29)}$ Considering its anthropophilic behavior, high density and possible infection with Leishmania parasites, $P$ s. davisi is incriminated in the enzootic and zoonotic cycles of CL in the Amazon Region. ${ }^{(33,35,39,41)}$ Our blood gut-content analysis also supports the involvement of this sandfly species in the enzootic transmission cycle in Brasiléia.

The species Ny. shawi is considered anthropophilic ${ }^{(42)}$ and is involved in the CL cycle transmission in Bolivia, where it has been found to be positive for $L$. (V.) braziliensis and $L$. (V.) guyanensis, ${ }^{(43)}$ whereas until now its potential to act as vector of CL agents in Brazil still needs confirmation. Similar to the findings of García et al. ${ }^{(43)}$ in Brasiléia, which shares a border area with the municipality of Cobija in Bolivia, DNA of both L. (V.) braziliensis and $L$. (V.) guyanensis parasites was identified in $N y$. shawi (four $/ 180,2.2 \%$ total positivity), captured in

TABLE VII

Correlation of sandfly species with the blood gut-content and parasite species identified in the blood meal of engorged females

\begin{tabular}{|c|c|c|c|c|c|c|}
\hline \multirow[b]{2}{*}{ Species } & \multirow[b]{2}{*}{ Blood meal (cyt b) } & \multirow[b]{2}{*}{ Area-R/trap } & \multirow[b]{2}{*}{ Parasite species $(h s p 70)$} & \multicolumn{2}{|c|}{ BLAST analysis } & \multirow[b]{2}{*}{ Total } \\
\hline & & & & E-value & $\begin{array}{c}\text { Identity } \\
(\%)\end{array}$ & \\
\hline Lutzomyia sp. & Low-quality sequences & A1-R4/HP ground & L. (V.) braziliensis & $9 e-42$ & 89 & 1 \\
\hline \multirow{2}{*}{ Nyssomyia umbratilis } & \multirow{2}{*}{ NI } & A4-R18/HP ground & Endotrypanum & $5 e-80$ & 98 & 1 \\
\hline & & A4-R18/Shannon & No identity & - & - & 1 \\
\hline \multirow{2}{*}{ Psathyromyia aragaoi } & NI & A3-R13/HP ground & L. (V.) shawi & $2 e-68$ & 100 & 1 \\
\hline & Homo sapiens & A3-R13/Shannon & Endotrypanum & $2 \mathrm{e}-83$ & 99 & 1 \\
\hline Psathyromyia sp. & NI & A3-R13/HP tree & L. (V.) braziliensis & $2 \mathrm{e}-68$ & 100 & 1 \\
\hline \multirow{2}{*}{ Psychodopygus davisi } & Coendou prehensilis & A1-R4/HP tree & Endotrypanum & $2 \mathrm{e}-83$ & 99 & 1 \\
\hline & $\mathrm{NI}$ & A1-R4/Shannon & Endotrypanum & $2 \mathrm{e}-83$ & 99 & 1 \\
\hline Sciopemyia sordellii & Homo sapiens & A7-R74/HP ground & L. (V.) guyanensis & $2 \mathrm{e}-68$ & 100 & 1 \\
\hline
\end{tabular}

Total

NI: not identified; R: Ramal (defined by the distance in kilometres along the Trans Pacific Federal Highway BR 317). 
the dense forest environment in light traps on the ground and Shannon. These two parasites were also identified by our group in cutaneous lesions of individuals living in Brasiléia. ${ }^{(44)}$ According to the essential criteria of KillickKendrick, ${ }^{(45)}$ these results provide further elements on the putative vector role of $N y$. shawi regarding $L$. (V.) braziliensis and $L .(V$.) guyanensis enzootics in the study area. In the blood gut-content analysis, Homo sapiens DNA was identified in this sandfly species, providing support for its anthropophilia in the region. Recently, flagellates were observed in the mid and hind portions of the gut in Ny. shawi captured in Xapuri, ${ }^{(27)}$ a municipality of Acre bordering Brasiléia, as well as in Assis Brasil, another neighbouring municipality, leading to a discussion about the potential vector role of $N y$. shawi in the three-border area of Brazil, Bolivia and Peru. ${ }^{(26)}$

$N y$. umbratilis is the main vector of $L$. (V.) guyanensis and is considered a fairly anthropophilic species. ${ }^{(46)} \mathrm{A}$ study carried out in Peixoto de Azevedo, in Mato Grosso state, showed a possible association of $N y$. umbratilis with the transmission of $L$. (V.) braziliensis, ${ }^{(47)}$ reinforcing our results regarding the identification of this parasite in one specimen of $N y$. umbratilis (one/44, 2.27\%) captured in light trap on top of tree in area A3-R13 of forest environment.

A single specimen of $N y$. antunesi tested positive for L. (V.) braziliensis DNA (one/19, 5.26\%) and was captured in light trap on the ground in the peridomicile (area A2-R5). This species has been associated with wild animals and peridomiciliary environments ${ }^{(48)}$ and also occurs in Peru and Bolivia. ${ }^{(13)} \mathrm{A}$ previous study in Acrelândia (state of Acre) reported this species in a high frequency $(59.1 \%)$ in the peridomicile environment and forests edges; ${ }^{(7)}$ in Rio Branco, $N y$. antunesi was found in low abundance in forest environments. ${ }^{(29)}$ This species has been associated with foci of visceral ${ }^{(49)}$ and CL, ${ }^{(50)}$ being also regarded as a suspected vector of $L$. (V.) lindenbergi in the state of Pará. ${ }^{(48)}$

One solely Ps. hirsutus hirsutus captured in Shannon in the forest environment (area A4-R18) was found positive for L. (V.) braziliensis (one/17, 5.9\%). Other works show this species as a potential vector of $L$. $(V$.) braziliensis and L. (V.) naiffi in the Amazon Region. $(24,35,46)$ In the municipality of Xapuri, Ps. hirsutus hirsutus was recently identified as having been parasitised by flagellated forms. ${ }^{(27)}$

For the other species with positive results on the search of Leishmania DNA (Ev. termitophila, Pintomyia sp., Pi. nevesi and Brumptomyia sp.), the high detection rates corresponded to a lower number of captured individuals (or few specimens submitted to molecular diagnosis) and with only one positive sample (Tables IV and V). It is important to highlight the first report of the finding of $L$. (V.) braziliensis DNA in Ev. termitophila and Brumptomyia sp. in the state of Acre; both sandflies were captured in light traps on the ground in the A2-R5 peridomicile area. Recently, DNA of this parasite was also found in Pi. nevesi captured in Rio Branco. ${ }^{(29)}$ In eight phlebotomine species it was not possible to infer the identity of the species of Leishmania (Ny. shawi, Nyssomyia sp., Ny. whitmani, Pintomyia sp., Ps. amazonen- sis, Psychodopygus sp. and two samples of Ps. davisi).

The relatively low identity value of $89 \%$ obtained for $L$. (V.) braziliensis DNA in one specimen from each of $N y$. umbratilis, Pi. nevesi and Ps. davisi may reflect the high intraspecific variability found for the "braziliensis complex" in Acre. ${ }^{(51)}$ In two species of sandflies, $N y$. shawi and Psychodopygus sp., it was possible to confirm $100 \%$ identity for L. (V.) guyanensis. Despite the high abundance of Ps. carrerai carrerai, for which 293 specimens were captured in all areas of forest environment, we did not find any positive sample for the presence of Leishmania DNA. Similar results were obtained in Rio Branco, where this species, together with PS. davisi, were the most abundant and a positive result for $L$. $(V$.) braziliensis detection was only observed in one specimen of Ps. davisi. ${ }^{(29)}$

The state of Acre in the Amazon Region has an extensive biological representativeness, comprising almost $40 \%$ of the mammal's species in Brazil and $4.5 \%$ worldwide. Several of these wild animals in Acre could represent a permanent food supply for sandflies. ${ }^{(52)}$ By studying the blood gut-content of these insects, it is possible to infer possible reservoirs acting in the maintenance of the enzootic cycle and better assessing the degree of anthropophilia of suspected vector species. ${ }^{(53)}$ In the present study, the blood gut-content analysis was able to properly identify 13 mammalian species in 39 sandfly samples. Interestingly, Homo sapiens represented the main source of feeding detected in these specimens $(41.02 \%)$. Female sandflies fed on humans were captured in all areas of forest and peridomicile environments, with the exception of area A6-R69 (peridomicile) that did not present engorged females. From these, $87.5 \%$ were captured in the dense forest areas, corroborating with the human local activities in the wild environment for the extraction of wood, oils, fruits, rubber and hunting. More than half of the sandfly species whose blood gut-contents were identified, included at least one specimen that had fed on human blood. For example, in Ny. shawi, Nyssomyia sp., Trichophoromyia sp. and Ev. saulensis, more than one individual that had fed on humans was identified. As discussed previously, $N y$. shawi is considered anthropophilic ${ }^{(42)}$ and probably affects the transmission of $L$. (V.) braziliensis and L. (V.) guyanensis in Bolivia. ${ }^{(43)}$ In Rio Branco, Ev. saulensis was the most abundant species in the captures using Shannon and with dominance in the forest environment, confirming its anthropophilic behavior. $^{(29)}$ Other studies also highlight the role of $E v$. saulensis and Trichophoromyia sp. as possible vectors in the state of Acre. ${ }^{(26,29,54)}$ As recently discussed, the putative vector importance of some species of the Trichophoromyia genus (including those found in Acre) seems to be increasing, ${ }^{(28)}$ but as far as we know our results are the first to demonstrate the man-biting behavior of specimens of this genus. As mentioned before, the females identified as Trichophoromyia probably belong to Th. octavioi and Th. auraenis, since up to now they are not distinguishable. Ps. carrerai carrerai and Ps. llanosmartinsi, which were also found to have fed on humans in our work, have been confirmed as vectors of $L$. $(V$.) braziliensis in Bolivia. ${ }^{(30,32)}$ 
Among the wild animals identified in the blood supply samples, armadillos were the most frequent and were represented by two species, D. novemcinctus and $D$. kappleri, which were exclusively identified in females captured in the dense forest areas A1-R4 and A5-R59. The former was identified only in Ps. carrerai carrerai that showed more selective feeding habits, exhibiting four specimens fed on this same species of armadillo. Although more than a half of the engorged Ps. carrerai carrerai females have been captured in light traps at the top of trees, this sandfly is commonly found in resting sites with fallen leaves on the ground. ${ }^{(55)} \mathrm{A}$ comprehensive discussion on the vertical/horizontal dissociation between feeding and resting sites can be found. ${ }^{(56)}$ These authors report the capture of Ps. hirsutus hirsutus in trees canopy, including an infected one, and this might be interpreted as circumstantial evidence of a $L$. $(V$.) naiffi arboreal enzootic cycle involving other reservoirs in the Tapajós National Forest, Belterra municipality in the state of Acre. Nonetheless, $L$. $(V$.) naiffi's accepted reservoir is the nine-banded armadillo $D$. novemcinctus, an obligatory terrestrial mammal; ${ }^{(57)}$ although $L$. (V.) guyanensis has also been detected in this and in other armadillo species. ${ }^{(55)}$ On the other hand, it could just be a natural vertical migration of flies that became infected on the ground. An example of this is the vertical migration of $N y$. umbratilis that becomes infected from the arboreal two-toed sloth (C. didactylus), but transmission to man occurs at ground level when the fly descends from the canopy during the day. ${ }^{(57)}$ In our study, we identify one specimen of Ps. hirsutus hirsutus fed on B. taurus and captured on the top of tree, possible reflecting another example of natural vertical migration.

Samples identified as T. tetradactyla were the second most common food source among wild animals and sandflies fed on this species (Ps. davisi, Ps. amazonensis, Psathyromyia sp. and Evandromyia sp.) were captured in all traps in the dense forest environment, their natural habitat, in areas A3-R13, A4-R18 and A5-R59 and also in light trap positioned on the ground at the edge of the forest in area A2-R5 (peridomicile). The finding of Ps. amazonensis feeding on T. tetradactyla is curious, because this sandfly is likely to feed on armadillos (D. kappleri, D. novemcinctus). ${ }^{(58)}$ T. tetradactyla is currently the only species of anteater from which Leishmania was isolated, in which $L$. (V.) guyanensis and $L$. (L.) amazonensis were isolated in Brazil and Ecuador, respectively. ${ }^{(55)}$

In our study, other species of wild animals also played important roles in the ecoepidemiology of leishmaniasis and the maintenance of sandfly species. The order Marsupialia was represented by the species $M$. noctivagus and D. marsupialis, which were identified in the blood gut-content in two specimens of $P$ s. davisi captured in area A3-R13 of the dense forest environment. Didelphis is the genus with the greatest dispersion on the continent, and because of its synanthropic nature, it is one of the most investigated mammals relative to infection by Leishmania spp. ${ }^{(5)}$ D. marsupialis has been identified as being naturally infected by $L$. (L.) infantum, ${ }^{(59)} L$. (V.) braziliensis ${ }^{(60)} L$. (L.) amazonensis ${ }^{(61)}$ and L. panamensis. ${ }^{(62)}$ In relation to rodents, several works have identified different species infected by $L$. (L.) amazonensis, includ- ing species of Dasyprocta. ${ }^{(55,60,62)}$ In the present work, this genus was represented by the species $D$. fuliginosa. Another rodent identified here, A. paca, is the only wild species that was previously found to be infected by $L$. (V.) lainsoni in the state of Pará. ${ }^{(63)}$ Different species of Leishmania have been detected in C. didactylus. For example, this species of sloth is considered a potential reservoir of $L$. (V.) guyanensis, ${ }^{(60,64)}$ and in Brazil, infection by $L$. $\left(V\right.$.) shawi has also been reported. ${ }^{(46)}$ Representatives of Artiodactyla were also found in our work. The identification of sandfly females that had fed on domestic pigs ( . scrofa) and oxen (B. taurus), exclusively in area A3-R13, corroborates the local characteristics of this site, which was the only area of forest environment where pigs occurred in the peridomicile and with the presence of an ox-breeding site close to the capture area.

Engorged sandfly females subjected to the analysis of blood gut-content showed positive results for the presence of Leishmania DNA. Sequencing results revealed samples with $100 \%$ identity to $L$. (V.) shawi, L. (V.) braziliensis and L. (V.) guyanensis from $P a$. aragaoi, Psathyromyia sp. and Sc. sordellii, respectively. Due to the blood gut-contents of these sandflies, we cannot associate them with the transmission of Leishmania in the studied areas. Beyond this, it cannot be ascertained that the tested blood and Leishmania have been ingested in the same occasion. A second blood meal after Leishmania infection (from another blood) is also possible. These results suggest that infection could be an occasional finding and that these insects have had previous contact with potential reservoirs of these species of Leishmania in the sampling areas (A1-R4 for L. braziliensis, A3R13 for L. braziliensis and L. shawi, and the peridomicile area A7-R74 for L. guyanensis). The presence of the parasite Endotrypanum was identified in females of $N y$. umbratilis, Pa. aragaoi and Ps. davisi. Relative to the last, correlation with the probable mammalian host was possible in only one of the females, in which the species Coendou prehensilis was identified in area A1-R4 (light trap on top of tree). Pa. aragaoi is recognised as showing preference for feeding on dasipodids such as armadillos (known to harbour Leishmania species, parasites of the Trypanosoma genus and Endotrypanum) and uses the refuges of these animals as resting places ${ }^{(55,62)}$ Here, the specimen of Pa. aragaoi presenting Endotrypanum DNA was captured in area A3-R13 (Shannon) and human blood was identified in its gut-content; probably, this female was already parasitised by Endotrypanum spp. and had performed a recent blood meal on humans. The identification of Endotrypanum spp. parasites is noteworthy; these parasites only occurred in samples of engorged sandflies, which has not previously been seen by our group in non-engorged females subjected to the diagnosis of Leishmania DNA-detection. Endotrypanum spp. belong to the Trypanosomatida order and are very closely related to Leishmania, being currently classified in the Paraleishmania section, which allowed their detection in the target kDNA analysis. ${ }^{(65)}$

This finding demonstrates the need to use complementary techniques, for instance hybridisation with specific probes and/or PCR targeting the hsp70 Leishmania gene, to accurately confirm the species or subgenera 
involved. By using this marker followed by sequencing the amplicons, we were able to demonstrate the presence of $L$. (V.) braziliensis, L. (V.) shawi and L. (V.) guyanensis, which are etiological agents of CL, circulating in the study area among sandflies and possible hosts/ reservoirs. These data are in agreement with previous analyses including CL patients in the state of Acre, in which highly diverse Leishmania species were isolated from clinical samples, including $L$. (V.) braziliensis, $L$. (V.) shawi, L. (V.) guyanensis, L. (V.) lainsoni, as well as possible mixed infections by $L$. $(V$. $)$ guyanensis/L. (L.) amazonensis and L. (V.) naiffi/L. (V.) lainsoni. ${ }^{(51,54,66)}$ These authors reinforced the hypothesis that the transmission of these parasites occurs with a higher frequency in rural/forest environments.

Overall, the data obtained in this study are highly relevant, bearing in mind that little is known about the agents, vectors and reservoirs that constitute the CL epidemiological chain in the state of Acre, a region of Brazil with high risk of contracting the disease by the human population.

\section{ACKNOWLEDGEMENTS}

To Fernando Azevedo Correia Centre of Health, in particular to Solange Kurvski, to FUNASA, for the support on sandflies captures, to the Municipality Department of Health, for the logistical support, to the residents of the study area and to the support of the sequencing platform of the Fiocruz in Rio de Janeiro. The authors declare no conflicts of interest.

\section{AUTHORS' CONTRIBUTION}

Conceived and designed the experiments: $\mathrm{CB}, \mathrm{RB}, \mathrm{AF}$, MB, DP-P, TA-P. Performed the experiments: TA-P, SMBG, ISP, AF, CS. Analysed the data: TA-P, DP-P, MB, FS, ISP, RLTS, AF, RB. Contributed with reagents/materials/analysis tools: RB, CB. Wrote the paper: TA-P, RB, CB. All authors read and approved the final manuscript.

\section{REFERENCES}

1. World Health Organization [Internet]. Geneva. Leishmaniasis. c2020 - [cited 2020 Feb 28]. Available from: http://www.who.int/ leishmaniasis/en/

2. Sistema de Informação de Agravos de Notificação [Internet]. Brasília (DF): c2019 - [cited 2020 Mai 6]. Available from: http://tabnet.datasus.gov.br/cgi/deftohtm.exe?sinannet/cnv/ltabr.def

3. Rangel EF, Lainson R. Ecologia das leishmanioses In: Rangel EF, Lainson R. Flebotomíneos do Brasil. Rio de Janeiro: Editora Fiocruz; 2003. p. 291-309.

4. Rangel EF, Lainson R, Carvalho BM, Costa SM, Shaw JJ. Sand fly vectors of American cutaneous leishmaniasis in Brazil. In: Rangel EF, Shaw JJ. Brazilian sand flies: biology, taxonomy, medical importance and control. Gewerbestrasse: Springer; 2018. p. 341-380.

5. Silva NS, Muniz VD. Epidemiologia da leishmaniose tegumentar americana o estado do Acre, Amazônia brasileira. Cad Saúde Pública. 2009;25:1325-36.

6. Silva NS, Viana AB, Cordeiro JA, Cavasini CE. Leishmaniose tegumentar americana no estado do Acre, Brasil. Rev Saúde Pública. 1999;33:554-9.

7. Silva-Nunes M, Cavasini CE, Silva NS, Galati EAB. Epidemiologia da leishmaniose tegumentar e descrição das populações de flebotomíneos no município de Acrelândia, Acre, Brasil. Rev Bras Epidemiol. 2008;11(2):241-51.
8. Borges DA, Molina SMG, Pinto MC, Galati EAB, Cesario M, Ortiz DGS. First record of Lutzomyia (Lutzomyia) longipalpis (Diptera: Psychodidae: Phlebotominae) on the Trinational Frontier (Brazil-Peru-Bolivia) of South-Western Amazonia. J Med Entomology. 2017;00(0):1-5.

9. Instituto Brasileiro de Geografia e Estatística [Internet]. Rio de Janeiro (RJ). c2019. - [cited 2020 Feb 28]. Available from: https:// www.ibge.gov.br/cidades-e-estados/ac/brasileia.html

10. Secretaria de Estado de Meio Ambiente. Recursos naturais: biodiversidade e ambientes do Acre. Programa Estadual de Zoneamento Ecológico. Rio Branco: Secretaria do Estado de Meio Ambiente; 2010 .

11. Forattini OP. Entomologia médica. Psychodidae, Phlebotominae, Leishmaniose, Bartonelose. Vol. IV. São Paulo: Edgard Blucher; 1973.

12. Galati EAB. Morfologia e taxonomia: morfologia, terminologia de adultos e identificação dos táxons da América. In: Rangel EF, Lainson R. Flebotomíneos do Brasil. Rio de Janeiro: Editora Fiocruz; 2003. p. 53-175.

13. Galati EAB. Morfologia e terminologia de Phlebotominae (Diptera: Psychodidae). Classificação e identificação de táxons das Américas. Apostila da Disciplina Bioecologia e Identificação de Phlebotominae. Programa de Pós-Graduação em Saúde Pública. São Paulo: Faculdade de Saúde Pública da Universidade de São Paulo; 2019. [cited 2020 May 06]. Available from: http://www.fsp.usp.br/egalati/ wp-content/uploads/2020/02/Apostila_Vol_I_2019.pdf

14. Marcondes CB. A proposal of generic and subgeneric abbreviations of phlebotomines sandflies (Diptera: Psychodidae: Phlebotominae) of the world. Entomol News. 2007;118:351-6.

15. Pita-Pereira D, Alves CR, Souza MB, Brazil RP, Bertho A, Barbosa A, et al. Identification of naturally infected Lutzomyia intermedia and Lutzomyia migonei with Leishmania (Viannia) braziliensis in Rio de Janeiro (Brazil) revealed by a PCR multiplex non-isotopic hybridization assay. Trans R Soc Trop Med Hyg. 2005;99:905-13.

16. Passos VM, Lasmar EB, Gontijo CM, Fernandes O, Degrave W. Natural infection of a domestic cat (Felis domesticus) with Leishmania (Viannia) in the metropolitan region of Belo Horizonte, state of Minas Gerais, Brazil. Mem Inst Oswaldo Cruz. 1996;91(1):19-20

17. Lins RM, Oliveira SG, Souza NA, de Queiroz RG, Justiniano SC, Ward RD, et al. Molecular evolution of the cacophony IVS6 region in sandflies. Ins Mol Biol. 2002;11(2):117-22.

18. da Graça GC, Volpini AC, Romero GA, Oliveira Neto MP, Hueb M, Porrozzi R, et al. Development and validation of PCR-based assays for diagnosis of American cutaneous leishmaniasis and identification of the parasite species. Mem Inst Oswaldo Cruz. 2012;107(5):664-74

19. Zampieri RA, Laranjeira-Silva MF, Muxel SM, Stocco de Lima AC, Shaw JJ, Floeter-Winter LM. High resolution melting analysis targeting hsp70 as a fast and efficient method for the discrimination of Leishmania species. PLoS Negl Trop Dis. 2016;10(2):e0004485.

20. Boakye DA, Tang J, Truc P, Merriweather A, Unnasch TR. Identification of bloodmeals in haematophagous Diptera by cytochrome B heteroduplex analysis. Med Vet Entomol. 1999;13:282-7.

21. Tamura K, Dudley J, Nei M, Kumar S. MEGA4: Molecular Evolutionary Genetics Analysis (MEGA) software version 4.0. Mol Biol Evol. 2007;24(8):1596-9.

22.Zang Z, Schwartz S, Wagner L, Miller W. A greedy algorithm for aligning DNA sequences. J Comput Biol. 2000;7(1-2):203-14.

23. Magurran AE. Measuring biological diversity. Oxford: Blackwell Science; 2004 
24. Azevedo ACR, Costa SM, Pinto MCG, Souza JL, Cruz HC, Vidal J, et al. Studies on the sandfly fauna (Diptera: Psychodidae: Phlebotominae) from transmission areas of American cutaneous leishmaniasis in state of Acre, Brazil. Mem Inst Oswaldo Cruz. 2008;103(8):760-7.

25. Araujo-Pereira T, Fuzari AA, Andrade Filho JD, Pita-Pereira D, Britto C, Brazil RP. Sandfly fauna (Diptera: Psychodidae: Phlebotominae) in an area of leishmaniasis transmission in the municipality of Rio Branco, state of Acre, Brazil. Parasit Vectors. 2014;7(360):2-5.

26. Teles CBG, dos Santos APA, Freitas RA, de Oliveira AFJ, Ogawa GM, Rodrigues MS, et al. Phlebotomine sandfly (Diptera: Psychodidae) diversity and their Leishmania DNA in a hot spot of American cutaneous leishmaniasis human cases along the Brazilian border with Peru and Bolivia. Mem Inst Oswaldo Cruz. 2016;111(7):423-32.

27. Brilhante AF, de Ávila MM, de Souza JF, Medeiros-Sousa AR, Sábio PB, de Paula MB, et al. Attractiveness of black and white modified Shannon traps to phlebotomine sandflies (Diptera, Psychodidae) in the Brazilian Amazon Basin, an area of intense transmission of American cutaneous leishmaniasis. Parasite. 2017;24:20.

28. Vasconcelos dos Santos T, Silveira FT. Increasing putative vector importance of Trichophoromyia phlebotomines (Diptera: Psychodidae) Mem Inst Oswaldo Cruz. 2020;115:e190284

29. de Ávila MM, Brilhante AF, Souza CF, Bevilacqua PD, Galati E, Brazil RP. Ecology, feeding and natural infection by Leishmania spp of phlebotomine sandflies in an area of high incidence of American tegumentary leishmaniasis in the municipality of Rio Branco, Acre, Brazil. Parasit Vectors. 2018;11:64.

30. Le Pont F, Desjeux P. Leishmaniasis in Bolivia. II. The involvement of Psychodopygus yucumensis and Psychodopygus llanosmartinsi in the selvatic transmission cycle of Leishmania braziliensis braziliensis in a lowland subandean region. Mem Inst Oswaldo Cruz. 1986;81(3):311-8.

31. Le Pont F, Breniere FS, Mouchet J, Desjeux P. Leishmaniasis in Bolivia. Psychodopygus carrerai carrerai (Barretto, 1946), new sylvatic vector of Leishmania braziliensis in lowland subandean region. CR Acad Sci Paris. 1988;307(III):279-82.

32. Bustamante M, Diaz M, Espinoza J, Parrado R, Reithinger R, García AL. Sandfly fauna in Chapare, Bolivia: an endemic focus of Leishmania (Viannia) braziliensis. J Med Entomol. 2012;49(5):1159-62.

33. Ogawa GM, Pereira AM Jr, Resadore F, Ferreira RGM, Medeiros JF, Camargo LMA. Sandfly fauna (Diptera: Psychodidae) from caves in the state of Rondônia, Brazil. Braz J Vet Parasitol. 2016;25(1):61-8

34. Silva AMD, Camargo NJD, Santos DRD, Massafera R, Ferreira AC, Postai C, et al. Diversidade, distribuição e abundância de flebotomíneos (Diptera: Psychodidae) no Paraná. Neotrop Entomol. 2008;37(2):209-25.

35. Gil LHS, Basano SA, Souza AA, Silva MGS, Barata I, Ishikawa EA, et al. Recent observations on the sand fly (Diptera: Psychodidae) fauna of the state of Rondônia, western Amazônia, Brazil: the importance of Psychdopygus davisi as a vector of zoonotic cutaneous leishmaniasis. Mem Inst Oswaldo Cruz. 2003;98(6):751-5.

36. Pereira AM Jr, Teles CBG, dos Santos APA, Souza Rodrigues MD, Marialva EF, Pessoa FAC, et al. Ecological aspects and molecular detection of Leishmania DNA Ross (Kinetoplastida: Trypanosomatidae) in phlebotomine sandflies (Diptera: Psychodidae) in terra firme and várzea environments in the middle Solimões region, Amazonas state, Brazil. Parasit Vectors. 2015;8:180.

37. Ready PD. Biology of phlebotomine sandflies as vectors of disease agents. Annu Rev Entomol. 2013;58:227-50.
38. Grimaldi G Jr, Momen H, Naiff RD, McMahon-Pratt D, Barrett TV. Characterization and classification of leishmanial parasites from humans, wild mammals, and sandflies in the Amazon region of Brazil. Am J Trop Med Hyg. 1991;44:645-61.

39. Souza AAA, Silveira FT, Lainson R, Barata IR, Silva MGS, Lima JAN, et al. The Phlebotominae fauna of Serra dos Carajás, Pará, Brazil, and its possible implication in the transmission of American tegumentary leishmaniasis. Rev Pan-Amazônica Saúde. 2010;1:45-51.

40. Teles CBG, Freitas RA, Oliveira AFJ, Ogawa GM, Cavalcante EA, Medeiros JF, et al. Description of a new phlebotomine species (Diptera: Psychodidae, Phlebotominae) and new records of sandflies from the state of Acre, northern Brazil. Zootaxa. 2013;3609:85-90.

41. Alves VR, Freitas RA, Santos FL, Oliveira AFJ, Barrett TV, Shimabukuro PHF. Sand flies (Diptera, Psychodidae, Phlebotominae) from Central Amazonia and four new records for the state of Amazonas, Brazil. Rev Bras Entomol. 2012;56:220-7.

42. Le Pont F, Mouchet J, Desjeux P. Distribution geographique et ecologique des phlebotomes (Diptera: Psychodidae) anthropophiles de Bolivie, sur un transect Andes-Amazonie. Ann Soc Ent. 1990;26(2):159-71.

43. García AL, Tellez T, Parrado R, Roja E, Bermudez H, Dujardin JC. Epidemiological monitoring of American tegumentary leishmaniasis: molecular characterization of a peridomestic transmission cycle in the Amazonian lowlands of Bolivia. Trans R Soc Trop Med Hyg. 2007;101(12):1208-13.

44. Araujo-Pereira T, Pita-Pereira D, Moreira RM, Silva-Galdino T, Oliveira- Duarte MP, Brazil RP, et al. Molecular diagnosis of cutaneous leishmaniasis in an endemic area of Acre state in the Amazonian Region of Brazil. Rev Soc Bras Med Trop. 2018;51(3):376-81.

45. Killick-Kendrick R. The life-cycle of Leishmania in the sandfly with special reference to from infective to the vertebrate host. Ann Parasitol Hum Comp. 1990;65(1):37-42.

46. Rangel EF, Lainson R. Proven and putative vectors of American cutaneous leishmaniasis in Brazil: aspects of their biology and vectorial competence. Mem Inst Oswaldo Cruz. 2009;104(7):937-54.

47. Azevedo AC, Souza NA, Meneses CR, Costa WA, Costa SM, Rangel EF. Ecology of sandflies (Dipetra: Psychodidae: Phlebotominae) in the north of the state of Mato Grosso, Brazil. Mem Inst Oswaldo Cruz. 2002;97:459-64.

48. Silveira FT, Ishikawa EA, de Souza AA, Lainson R. An outbreak of cutaneous leishmaniasis among soldiers in Belém, Pará state, Brazil, caused by Leishmania (Viannia) lindenbergi n. sp. A new leishmanial parasite of man in the Amazon Region. Parasite. 2002;9(1):43-50.

49. Ryan L, Brazil RP. Leishmania infections in Lutzomyia longipalpis (Diptera: Psychodidae) on the Island of São Luis, Maranhão state, Brazil. Mem Inst Oswaldo Cruz 1984;79:383-4.

50. Sánchez-Uzcátegui YDV, Vasconcelos-dos-Santos T, Silveira FT, Ramos PKS, dos Santos EJM, Póvoa MM. Phlebotomines (Diptera: Psychodidae) from a urban park of Belém, Pará state, northern Brazil and potential implications in the transmission of American cutaneous leishmaniasis. J Med Entomol. 2020;57(1):281-8.

51. Tojal AC, Cupolillo E, Volpini AC, Almeida R, Romero GAS. Species diversity causing human cutaneous leishmaniasis in Rio Branco, state of Acre, Brazil. Trop Med Int Health. 2006;11(9):1388-98.

52. Nascimento JS, Badarame AM, Dantas MMO, Urbanski AS, Carmo ECO, Ribeiro VMF. Wild species housed in animal sorting centers/Acre: conservationist implications. Semina Cienc Biol Saúde. 2016;37(1):63-76. 
53. Afonso MMS, Gomes AC, Meneses CRV, Rangel EF. Studies on the feeding habits of Lutzomyia (N.) intermedia (Diptera, Psychodidae), vector of cutaneous leishmaniasis in Brazil. Cad Saúde Pública. 2005;21:109-18.

54. Araujo-Pereira T, de Pita-Pereira D, Boité MC, Melo M, da Costa-Rego TA, Fuzari AA, et al. First description of Leishmania (Viannia) infection in Evandromyia saulensis, Pressatia sp. and Trichophoromyia auraensis (Psychodidae: Phlebotominae) in a transmission area of cutaneous leishmaniasis in Acre state, Amazon Basin, Brazil. Mem Inst Oswaldo Cruz. 2017;112(1):75-8.

55. Roque ALR, Jansen AM. Hospedeiros e reservatórios de Leishmania sp. e sua importância na manutenção dos ciclos de transmissão nos ambientes silvestre e sinantrópico. In: Conceição-Silva $F$, Alves $C R$. Leishmanioses do continente americano. Rio de Janeiro: Editora Fiocruz; 2014. p. 233-57.

56. Souza AAA, Vasconcelos dos Santos T, Jennings YLL, Ishikawa EAY, Barata IR, Silva MGS., et al. Natural Leishmania (Viannia) spp infections in phlebotomine sand flies (Diptera: Psychodidae) from the Brazilian Amazon Region reveal new putative transmission cycles of American cutaneous leishmaniasis. Parasite. 2016;23:22.

57. Ready PD, Lainson R, Shaw JJ, Ward RD. The ecology of Lutzomyia umbratilis Ward \& Fraiha (Diptera Pyschodidae), the major vector to man of Leishmania braziliensis guyanensis Floch in northeast Amazonian Brazil. Bull Entomol Res. 1986;76:21-40.

58. Kocher A, de Thoisy B, Catzeflis F, Valière S, Bañuls AL, Murienne J. iDNA screening: disease vectors as vertebrate samplers. Mol Ecol. 2017;26(22):6478-86.
59. Corredor A, Gallego JF, Tesh RB, Morales A, Ferro De Carrasquilla C, Young DG, et al. Epidemiology of visceral leishmaniasis in Colombia. Am J Trop Med Hyg. 1989;40(5):480-6.

60. Dedet JP, Gay F, Chatenay G. Isolation of Leishmania species from wild mammals in French Guiana. Trans R Soc Trop Med Hyg. 1989;5:613-5.

61. Grimaldi G Jr, Tesh RB, Mcmahon-Pratt D. A review of the geographic distribution and epidemiology of leishmaniasis in the New World. Am J Trop Med Hyg. 1989;41(6):687-725.

62. Ashford RW. Leishmaniasis reservoirs and their significance in control. Clin Dermatol. 1996;14:523-32.

63. Silveira FT, Lainson R, Shaw JJ, De Souza AAA, Ishikawa EA, Braga RR. Cutaneous leishmaniasis due to Leishmania (Leishmania) amazonensis in Amazonian Brazil, and the significance of a Montenegro skin-test in human infections. Trans R Soc Trop Med Hyg. 1991;85:735-8.

64. Gentile B, Le Pont F, Pajot FX, Besnard R. Dermal leishmaniasis in French Guiana: the sloth (Choloepus didactylus) as a reservoir host. Trans R Soc Trop Med Hyg. 1981;75:612-3.

65. Cupolillo E, Medina-Acosta E, Noyes H, Momen H, Grimaldi GJR. A revised classification for Leishmania and Endotrypanum. Parasitol Today. 2000;16:142-4.

66. Teles CBG, Medeiros JF, dos Santos APA, de Freitas LAR, Katsuragawa TH, Cantanhêde LM, et al. Molecular characterization of American cutaneous leishmaniasis in the triborder area of Assis Brasil, Acre state, Brazil. Rev Inst Med Trop. 2015;57(4):343-7. 